\title{
An Evolutionary Developmental Approach to Cultural Evolution
}

\author{
by Claes Andersson, Anton Törnberg, and Petter Törnberg
}

\begin{abstract}
Evolutionary developmental theories in biology see the processes and organization of organisms as crucial for understanding the dynamic behavior of organic evolution. Darwinian forces are seen as necessary but not sufficient for explaining observed evolutionary patterns. We here propose that the same arguments apply with even greater force to culture vis-à-vis cultural evolution. In order not to argue entirely in the abstract, we demonstrate the proposed approach by combining a set of different models into a provisional synthetic theory and by applying this theory to a number of short case studies. What emerges is a set of concepts and models that allow us to consider entirely new types of explanations for the evolution of cultures. For example, we see how feedback relations-both within societies and between societies and their ecological environment-have the power to shape evolutionary history in profound ways. The ambition here is not to produce a definitive statement on what such a theory should look like but rather to propose a starting point along with an argumentation and demonstration of its potential.
\end{abstract}

\section{Introduction}

Highly schematically one can speak of two dominant approaches to Paleolithic culture: (i) an ecological/economical approach (EA) that is largely based on behavioral ecology and economical constraints like time consumption, portability, and so on; (ii) a physiological approach (PA) that emphasizes physiology, in particular cognition, as an enabler and constraint on culture (see also Foley and Lahr 2003 for a similar factorization). Neither approach makes sense on its own, and controversy typically concerns the relative importance of the forces that they represent. Both moreover share a common neo-Darwinian model of adaptation where natural selection is seen as the sole provider of evolutionary direction; to the extent that other factors enter into consideration, they sit uneasily on the margins of this framework. ${ }^{1}$

The PA is pervasive but rarely championed explicitly; Richard Klein typically serves as its embodiment (and lightning

Claes Andersson is Assistant Professor in the Complex Systems Group, Division for Physical Resource Theory, Department of Energy and Environment, Chalmers University of Technology (412 96 Göteborg, Sweden [claeand@chalmers.se]). Anton Törnberg is a $\mathrm{PhD}$ candidate and graduate research assistant in the Department of Sociology and Work Science, University of Gothenburg (Box 720, 40530 Göteborg, Sweden). Petter Törnberg is a PhD candidate and graduate research assistant in the Complex Systems Group, Division for Physical Resource Theory, Department of Energy and Environment, Chalmers University of Technology (412 96 Göteborg, Sweden). This paper was submitted 29 VIII 12, accepted 9 II 13, and electronically published 13 III 14. rod) in the literature (Klein 1995, 2000; Klein and Edgar 2002). Its persistence stems largely from that it is hard to see how a cognitive technological potential could have persisted untapped over extended periods of time. This logic dictates that technological stasis and transitions must be tied to cognitive capabilities that, due to strong selection for the tools and strategies that they afford, would rapidly come to realize their highest expressions. These capabilities are typically envisioned as providing distinct powers — such as the ability to conceive of higher dimensional structure, symbolism, multicomponent tools, and so on-that will leave distinct traces in the archaeological record. Transitions would then be true watershed events, triggered by the advent of new cognitive capabilities and marking the first appearance of new behavior and the last appearance of old obsolete behavior, with the best known example no doubt being the concept of "behavioral modernity" (see, e.g., Henshilwood and Marean 2003).

The EA is often contrasted to the more paleontological (in terms of both artifact and hominid taxonomy) approach of the PA. It emphasizes geographically and temporally varying environmental selection pressures, and cognition is seen more as a capability for variability than as a set of fixed capacities. The EA therefore maintains a much more generous comfort level to archaeology and paleontology being "out of sync," such as when one hominid form exhibits considerable vari-

1. Indeed, elements of developmental reasoning can be found throughout the paleoanthropology literature, and we will employ several of these elements; examples include the invention cascades model by Schiffer (2005), the broad spectrum hypothesis by Flannery (1969), the role and significance of modified lithic technology outlined by Davidson and McGrew (2005), and the evolution of home bases by Rolland (2004). 
ation in cultural style and complexity (e.g., within H. sapiens), or when several hominid forms share style and complexity (e.g., between $H$. sapiens and $H$. neanderthalensis). So since there is indeed a considerable "lack of sync" between hominid stones and bones, the PA has come to be seen by many as a Procrustean bed for archaeology, picking and choosing what appears to be of use for reconstructing an elegant hominid phylogeny.

To mention only a small selection of reviews and finds that contribute to the feeling that the PA is under siege empirically, McBrearty and Brooks (2000) and McBrearty (2007) consider a wide range of Middle Stone Age (MSA) reports of artifact types often taken to be diagnostic of the Upper Paleolithic (UP). In a recent review, Shea (2011) finds that the idea of Mode 4 technology being unique to some behaviorally modern UP/Later Stone Age (LSA) variant of $H$. sapiens has no archaeological support. McCall (2006) and Soriano et al. (2007) review the MSA Howiesons-Poort evidence concluding that it was a separate and recursive tradition not ancestral to UP technology. Hovers and Kuhn (2006) collect studies of intermittent "modernity" in the European Lower Paleolithic (LP) and Middle Paleolithic (MP). Schlebusch et al. (2012) revealed, based on genetic evidence, that the Khoe-San of southern Africa diverged as a group circa 100 kya (kya = 1,000 years ago), which is at least 50 kya before the UP/LSA and a presence of $H$. sapiens outside of Africa and the Levant. Some LP sites, moreover, give evidence of notable complexity in nonlithic culture, for example, Gesher Benot Yaaqov (Goren-Inbar 2011), Schöningen (Thieme 1997, 2005), and Bilzingsleben (Mania and Mania 2005; Mania et al. 1994). Finally, Bednarik (2011) documents a large collection of possible paleoart finds from the LP and onward.

But the EA has still not been able to muster a satisfying alternative that really absorbs and defuses the PA account. First of all, the expected covariation between technology and biotopes does not become clearly manifest until well into the UP (Bocquet-Appel and Tuffreau 2009; Stiner and Kuhn 2006). Second, its explanations hover dangerously close to what in evolutionary biology is known as the just-so-story format (Gould and Lewontin 1979): in arguing how localized phenomena can be seen as environmentally adaptive, highly specific hypotheses may be produced, but these may be blamed for offering little beyond a restatement of their own basic assumption: "because it was adaptive." Cultural evolution appears as underdetermined as ever: sometimes changing dramatically for no apparent reason and sometimes sailing through substantial external stress without much change at all.

But we suspect an even more fundamental reason behind this chronic lack of a resolution. Neo-Darwinian models are based on a priori given selection pressures, which basically reduces adaptation to optimization. This general model of how evolutionary change happens is firmly entrenched and shapes questions and answers alike. ${ }^{2}$ It leads us into seeing processes as uninteresting transients, into assuming that change must be due to exogenous triggers, and into thinking that any and all features of an adapted system should match some feature of an environment that is external and autonomous. With no disagreement on this level between the EA and PA perspectives, there is full tacit agreement that there really should be a perfect match between potential and expressed cultural capability. When there is not, the resolution will be that we are wrong either about the capabilities or about the environment. Although culture frequently takes center stage, it is itself notably absent from the stage as a factor in its own evolution; there is no room for explanations having to do with how culture is organized, how it develops, and how it interacts with other processes in the neo-Darwinian framework (see also Sterelny 2011). The evolutionary constraints that the PA and EA represent are clearly supremely relevant, but could the whole underlying model of adaptation be misguided?

The present work represents the view that the evolution of culture is channeled by endogenous developmental mechanisms and an intermingling between cultural and noncultural processes. By this, culture does not only become a crucially important factor in its own evolution, it also becomes coupled with processes unfolding over both longer and shorter scales of time and space. We argue that we need to develop what we call an evolutionary developmental approach if we are to understand the origins and history of culture, and we view our effort as a direct parallel of the corresponding approach to evolutionary biology (see, e.g., Arthur 2011; Odling-Smee et al. 2003; Oyama, Griffiths, and Gray 2001).

The ultimate purpose of this paper is to advocate an evolutionary developmental approach to studying sociotechnical evolution. To do this, we will develop a provisional evolutionary developmental theory by combining a set of complementary models that all illuminate innovation processes in different ways and on different levels of organization. We will apply this theory to a set of brief case studies. The aim is not to provide a final statement but rather to propose a starting point and a way of being more concrete than what an argument entirely in the abstract would have been.

We begin by motivating the need for such a theory in general. We then introduce the three models that we will adapt and combine, developing a synthesis as we go along. The concepts introduced are next elucidated using two short case studies: the first focusing on organization and the second on process. This is followed by a discussion about transitions, stasis, and adaptation, and why the record of lithic technology can be expected to poorly represent hominid capabilities and adaptability.

2. Equilibrium models based on such an optimization logic can certainly be highly useful. What we take issue with is the (often tacit) implication that it usefully characterizes the overall evolutionary process. 
The Evolutionary Development of Sociotechnical Organization: A Synthetic Model

\section{Why We Need Evolutionary Developmental Models}

Early Homo was the first animal as far as we know that had in its possession a piece of knowledge that could not be biologically inherited and that it simply could not afford to lose. But summoning culture to our service was a Faustian bargain: its tremendous powers came at the price of eternal servitude. It also set the stage for an extensive coevolution between hominid culture, ecological niche, and physiology. Socially and materially transmitted culture truly became a part of us and we of it; it is shaped around us, and we around it, just like any organ that happens to be a material part of our bodies.

The relation between ourselves, culture, and our environment mirrors that between heritable material, organism, and environment, and the latter set of relations has been explored by evolutionary developmental theories in biology. Evolutionary developmental biology (see, e.g., Arthur 2011) tells us that variation, and thereby evolution, cannot be understood at the genetic level-in particular, not if we are interested in evolution in the long run. Put simply, variation in phenotype must happen via variation in developmental trajectories, so development strongly determines what can and cannot arise, and while genes play a central role in development, their role is highly complex and cannot be disentangled from the rest of the developmental system. Niche construction theory (see, e.g., Laland et al. 2007; Odling-Smee et al. 2003) goes even further and breaks apart the neo-Darwinian delimitation between what adapts and what gets adapted to. It sees organisms as not just adapted to their ecological environments but also as adapting their environments to themselves. In the end, it becomes impossible to decouple these processes from each other. This position and approach to studying evolutionary biology are also represented in a more generalized form in developmental systems theory (see, e.g., Griffiths and Gray 1994; Oyama et al. 2001).

These arguments apply even more strongly for culture, where social structure, institutions, artifacts, and environmental modifications constitute an adapted system that is also the engine of its own adaptation. As evolution unfolds, this apparatus is all the time present: it catalyzes, scaffolds, and gets modified by evolutionary change both internally and externally. Ideas, cultural representations, memes, routines, or whatever we want to call them here, play a role roughly analogous to genes (although not quite; see, e.g., Andersson 2008, $2011 b$ ), which is to say that they are necessary but only in a wider developmental context. So just like proponents of evolutionary developmental theories argue that we must understand ontogeny and the interplay between organisms and their environment in order to understand organic evolution, we argue that we must understand the processes and structures of culture as well as how they interact with noncultural processes in order to understand the evolution of culture.
These developmental theories challenge the neo-Darwinian view of evolutionary change in ways that we believe are at least as important for understanding how culture evolves. We think that many of the current paradoxes and enigmas in hominid evolution may be theoretical artifacts rather than true features of the system under study; a simple change of perspectives may turn some of these paradoxes into workable problems or even dissolve them (see also Sterelny 2011). For example, on a developmental view, the absence of notable external change no longer implies stasis, nor the other way around. Questions of the nature-or-nurture type are no longer posed on either a binary either-or form or a quantitative form; saying that something is $70 \%$ due to genetic factors makes as little sense as saying that the operation of an internal combustion engine is $70 \%$ due to the fuel and $30 \%$ to its mechanics. Also, large effects do not necessarily call for large causes, and the original causes of large effects may well be mundane, idiosyncratic, and probably impossible to find out anyway. Besides, they are no longer even the most interesting part of the story. What is really interesting are the processes and organization that often stabilize the system but that sometimes amplify small events into landslides. These processes combine environmental, physiological, and cultural factors, and they are weaved together in bootstrapping processes that largely feed on themselves; exogenous events and processes of course remain important, but they are not the sole sources of explanations.

If there is a need to frame Darwinism differently in evolutionary biology, it would hardly be surprising if it needed to be framed differently in paleoanthropology too. But we cannot use biological theories as they stand to understand culture. In fact, biological theories of this sort will mostly be used as a source of overarching inspiration. We will mostly use elements from innovation research set in present times, where the processes and organization of societies are there studied together in a way that suits our purposes. What we do here is select three models that each cover an important part of the dynamics that we think should be better understood in cultural evolution. Together they become more than their sum; they have to be readapted from their original areas of application, and we need to stitch them together into a coherent framework. We will do this as we introduce them.

\section{Exaptive Bootstrapping}

First out is what we call the exaptive bootstrapping model (see Lane 2002, 2011; Lane and Maxfield 2005; Lane et al. 2009). Innovation ${ }^{3}$ processes are conceptualized as transformation processes in an agent-artifact space where any transformation potentially triggers a reconfiguration of the entire fabric. New configurations of agents may change how artifacts

3. We use the distinction between invention and innovation introduced by Schumpeter (1934), where innovation is the process by which inventions become adopted and fixed in the population. 
are used and trigger changes in the artifacts. These changes in turn have an impact on agents' roles and interactions. Five steps in what we call the internal innovation cycle are identified: “(i) new artifact types are designed to achieve some particular attribution of functionality; (ii) organizational transformations are constructed to proliferate the use of tokens of the new type; (iii) new patterns of human interaction emerge around these artifacts in use; (iv) new attributions of functionality are generated to describe what the participants are obtaining or might obtain from them; (v) new artifacts are conceived and designed to instantiate the new attributed functionality" (Lane 2011, 69). Since points i and v coincide, we have a bootstrapping process that, since each cycle may lead to more than one new cycle, is prone to cascading.

Exaptation (Gould and Vrba 1982) - the principle by which an artifact can be put to uses other than those originally intended-enters between steps iii and iv and is identified as a major mode of innovation (see also, e.g., Davidson and McGrew 2005; Rolland 2004), where the exaptive process is described but not named). The internal innovation cycle brings out the dichotomy of radical versus incremental innovation, where the former involves changes in function while the latter is of a faster-better-cheaper type. The latter is less prone to cascading, since it does not directly disrupt configurations in agent-artifact space. ${ }^{4}$

To further illustrate how internal innovation cycles can play themselves out, let us consider the application of culturally transmitted strategies. Application of cultural knowledge entails a production of situational knowledge that adapts and combines strategies to local conditions. Most such knowledge is for immediate use and discard (Lorentz 1977). Some will, however, be candidates for generalization and incorporation into the culturally transmitted package. So by simply using culturally carried knowledge, possible improvements in the zone of proximal development (Vygotsky 1978) will reveal themselves to the practitioners (Schiffer 2005). This process is necessary for adaptation to changing circumstances to be possible: retaining what appears to work, removing what appears not to work, and solving problems. Each addition will furthermore reveal new sets of possible novelty, calling for even more change in a cascading mode of growth.

Davidson and McGrew (2005) explain how lithic technology may be crucial in this respect, since it lends itself to general usage of exceptionally wide applicability, such as cutting, scraping, and piercing. Apart from affording the potential to branch out into many types of more specialized tools, lithic tools may also be used for fashioning (and from the early MP/MSA become part of; see, e.g., Mazza et al. 2006; Rots and Van Peer 2006; Rots et al. 2011) secondary implements, giving a tremendous leverage on their range of uses and on

4. It might however also cause cascades under certain circumstances, e.g., via threshold effects. If the cost of some practice drops, it may suddenly become useful in applications that were formerly uneconomical; this would lead to exaptation and functional change. their propensity for generating open-ended skill systems. Around these implements, new patterns of use may appear, paving the way for ever more addition and change. Just as important in this respect may be the rarity of suitable raw material, as evidenced by its conscious transportation already in the Oldowan (e.g., Braun et al. 2008; Stout et al. 2010). Even without diversifying or specializing function, there was a consistent potential for sophistication through the entire production chain, from raw material procurement to tool use: higher quality raw material, caching of raw materials and tools, exchange, sharing, control over the shapes of produced flakes, retouch of worn tools to renew or change properties, and so on (for a review of how lithic technological organization is currently viewed, see Andrefsky 2009).

But there are also innovation processes meditated by environmental and physiological systems. If we look at the internal innovation cycle as analogous to evolutionary developmental biology processes, the external innovation cycle can be seen as the sociotechnical counterpart of niche construction.

Let us consider a hypothesis about the MP-UP transition along lines similar to the broad spectrum revolution hypothesis (Flannery 1969; Stiner et al. 2000) and mutual exclusion between cultural groups (O'Connell 2006). The LP and MP saw a development from a broad opportunistic subsistence base (e.g., Steele 2010) toward a more narrow subsistence focused on big game predation (e.g., Hoffecker 2009; PérezPérez et al. 2003; Villa and Lenoir 2009). With the UP, this development is followed by a new broadening of the subsistence base, where big game hunting is complemented by a much wider array of low-level resources (see, e.g., Hoffecker 2009; Richards and Trinkaus 2009; Richards et al. 2000; Stiner et al. 2000). This development can be tied to the emergence of higher technological variability in UP technology (see, e.g., Hoffecker 2009; Kuhn and Stiner 2001; Stiner and Kuhn 2006), and it can be suspected to produce an ecological ratchet effect (see fig. 1). A broader subsistence base reduces risk and increases the ecological carrying capacity, which leads to higher population density. This would in turn inevitably lead to smaller areas per capita for subsistence and to the destruction of the previous niche of relying more heavily on big game. So there is no going back from such innovations, and for each step that is taken the pressure to take another step in the same direction will remain strong.

External innovation cycles may continually have operated on any scale and via any external system that can act as a ratchet, most importantly physiological adaptation such as changed cognitive capabilities. Its main preconditions may have been around for a long time, and its trigger would be some kind of novelty behind which an unknown amount of generativity happens to hide. Such a portal innovation may be entirely inconspicuous since its generativity is not intrinsic to it: each step creates the conditions for new steps and acts in various ways to block backsliding. It is thought, for example, that modified lithics arose in relation to large mammal 


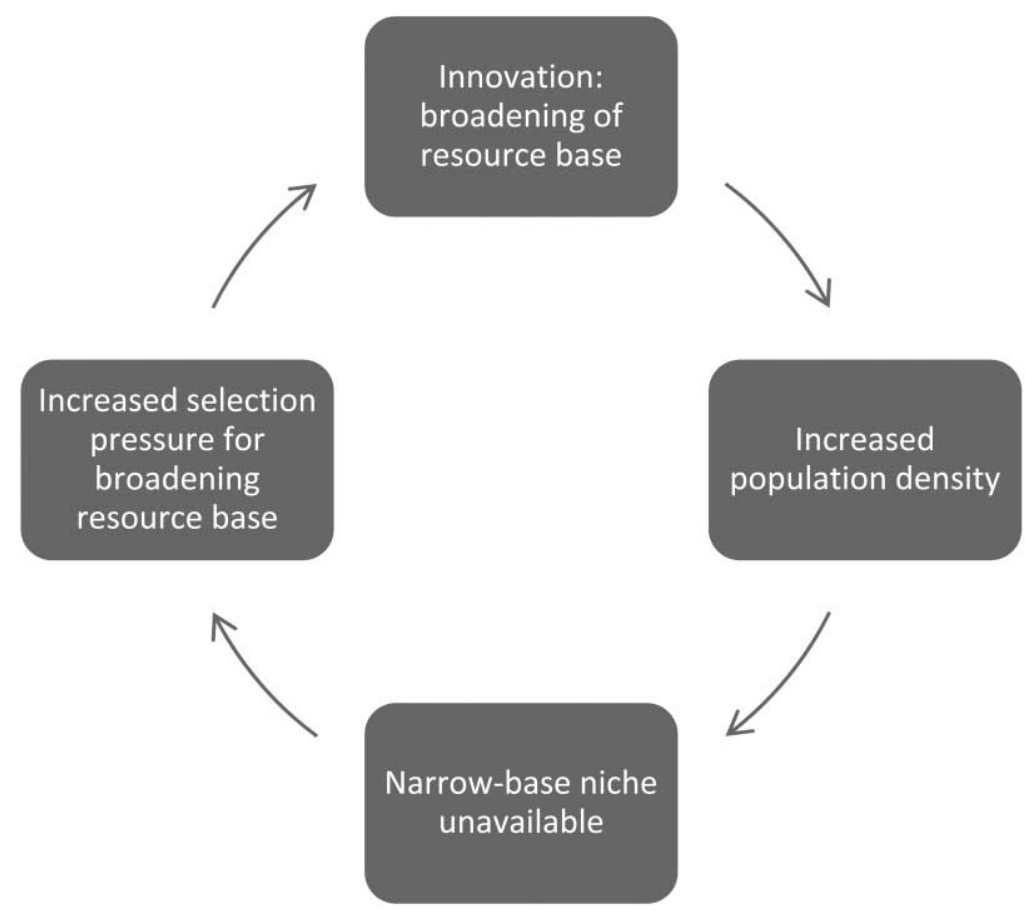

Figure 1. Possible bootstrapping cycle maintaining pressure for sociotechnical change. Such a positive feedback loop could keep on going as long as the sociotechnical system afforded new paths forward.

scavenging (e.g., Heinzelin et al. 1999; Semaw et al. 2003; Domínguez-Rodrigo et al. 2005); the future generativity of this technology millions of years down the line obviously played no role in its original adoption and development.

\section{Generative Entrenchment}

The generative entrenchment model (Wimsatt 1999; Wimsatt and Griesemer 2007) was originally devised in evolutionary biology as a model of how new features always assume the presence of, and adapt to, earlier features. If exaptive bootstrapping describes the explosive side of innovation, generative entrenchment describes how basically the same processes cause the dynamics to jam up to generate powerful dynamical lock-in effects. The central insight is that apart from the fitness of the novelty itself, we must also consider the fitness of the cascade of reconfigurations that must take place for novelty to fit into an existing and fine-tuned system. The more fundamental the locus of change, the more other things will be affected by the change, so the larger will the cascade effects be and the higher the likelihood that it will bring about maladaptive effects that cancel whatever benefit that the original novelty brought. This tends to lead-as it has in the organization of genetic networks (Shubin et al. 1997), biological body plans (Arthur 2011), and modern society (Wimsatt 2013) - to a hierarchy whose low-level parts have general and abstract functions that rarely change and whose high-level parts are progressively more adaptively flexible.
Generative entrenchment brings out a second spectrum of innovation types: deep versus superficial innovation. Deep innovation affects lower parts of the hierarchy, tending to triggers larger cascades. These will be rare but have dramatic and sweeping effects. Superficial innovation affects higher and more flexible parts and tends to generate smaller cascades. They will be more frequent and less disruptive. Radical innovation is therefore progressively less likely to enter into the system the more fundamental the affected component is. Substantive refinement of function through incremental innovation will however be present in fundamental components since these are likely to remain for a long time in a stable context. In effect, this means that the bottom levels will be selected for exaptability through generality: the wider the range of functionalities that they afford in dependent parts further up in the hierarchy, the more adaptable will the system as a whole be.

\section{The Multilevel Perspective}

Also addressing the proneness of cultures to lock-in is the multilevel perspective (see Geels 2010; Geels and Kemp 2012; Geels and Schot 2007), which focuses on what conditions that need to obtain for fundamental transitions to take place. Different areas of activity—say, storage, food preparation, domestic fire handling, construction of dwelling structures, foraging, hunting, raw material procurement, and so on-would here be referred to as sociotechnical regimes organized into a 
sociotechnical system. Regimes evolve to become specialized and separated to reflect differences in function. But at the same time they will become entangled and coordinated: horizontally because they are all part of a larger project of maintaining the well-being of the society and vertically because they will rely on and share more entrenched and fundamental technology and practices.

Regimes will come to serve certain functions in relation to one another, and by fitting well into the sociotechnical system, important and well-connected regimes have an "internal fitness" that can trump even substantial "external fitness" of challenging regimes. ${ }^{5}$ Regimes will also be resilient to radical changes in their function for the exact same reason. Most innovation will be incremental and channeled into the regimes, essentially making them better, faster, and cheaper while preserving their function. Moreover, the hierarchical arrangement described by generative entrenchment will apply both within and between regimes: some parts of them will be more free to change while others will be more entrenched, and in the same way, some regimes will be more dynamical and others more static.

The sociotechnical system, along with all other relevant aspects of the environment (other groups, ecology, climate, etc.), collectively form what is referred to in the multilevel perspective as a landscape. Changes and shifts in this landscape are generated both within and outside of the sociotechnical system, often gradually and over time. Since the landscape contains the regimes, it will pull these, as it were, and generate stress in their configurations. As stress builds, rifts may form in the sociotechnical system as regimes come to fit in poorly, reducing their internal fitness, and offering windows of opportunity for fundamental change.

Whether or not a transition really will take place depends on the availability of challenging minor regimes. ${ }^{6}$ Minor regimes fill important but more specialized roles, and they serve an important role in the innovation dynamics because they sometimes turn out to be exaptable into more major roles. Modern examples include things like specialized types of propulsion, materials, energy production, and so on in niche applications (e.g., military, space) where ad hoc inventiveness is called for, or for that matter major regimes unique to certain countries, cultures, and so on. The reason why regime-level radical innovation needs a long period of relative isolation as a minor regime is that whole new systems of practices do not appear overnight and a minor regime must have developed

5. A modern example is the use of fossil fuels. Everything from engine designs to extraction (of resources), conversion (into fuel), distribution (of fuel), consumer expectations, infrastructure, and workforce training are finely tuned and adapted to their use. So even if new technologies have a demonstrably better potential, they will still face an uphill battle: the incumbent technology has constructed the entire niche in which the fight will play itself out.

6. Referred to as niches in MLP—a terminology choice that we think would be confusing in this context. quite a bit before it can hope to take on even a crippled major regime.

\section{Brief Demonstrations}

We will here employ the concepts that we have introduced to analyze two brief case studies. The primary purpose is to demonstrate the applicability of the framework to historical processes more in general, to test whether the framework promises to have any bite as a method for integrating and analyzing a heterogeneous collection of stylized facts.

\section{The Synthetic Model in Context}

Let us consider (mostly) the organization of Acheulean communities from the Gesher Benot Yaaqov (GBY) site ( 800 kya) as described by Goren-Inbar (2011). Rich assemblages are found in 15 horizons covering a time period of approximately $100 \mathrm{ky}$, and they provide evidence on a level of resolution that is rare for sites of such antiquity.

Two major regimes can be particularly well established: (i) raw material procurement and (ii) lithic production. GBY hominids primarily used basalt as raw material in their giant core Acheulean lithic technology. The basalt was quarried from nearby locations whose selection demonstrates intimate knowledge of rock properties relevant for tool production. Slabs were reduced to smaller pieces using methods out of which at least two have left persistent traces: large rock percussors and levers, the latter being inferred from characteristic notches present on slabs. Many parts of the quarrying practices cannot be reconstructed, but it is clear that quarrying must have been a collective activity. What emerges is a coherent sociotechnical regime consisting of a system of multiple types of artifacts, individuals, knowledge, and sites, and whose continuity can be confirmed over a time span of 50 ky (Sharon et al. 2011). Since it can be inferred, as Goren-Inbar (2011) does by considering an ethnographic case (Pétrequin and Pétrequin 1993), that considerable detailed knowledge and nontrivial strategies were needed, this continuity indicates that the regime was passed on across generations with great fidelity.

We can safely infer that the quarrying regime was particularly strongly entangled with the tool production regime. This regime can also be confirmed over a span of $50 \mathrm{ky}$ and was no less based on transmitted expert knowledge. Both soft and hard percussors were used, and a high level of knowledge and control is evidenced by the fact that despite great variability in blank properties, the resulting tools were remarkably uniform. Indicative of transmission is also a substantial similarity with African Acheulean tool types and morphology of the same era. Moreover, Goren-Inbar (2011) notes that basalt is hard to process, and basalt knapping is considered to represent the highest level of expertness among ethnographically studied biface knappers in Irian Jaya (Pétrequin and Pétrequin 1993).

We also see the base of a hierarchy: although the higher 
level regimes leave few persistent traces, the low-level lithic tools were obviously used in several roles. Some direct uses of lithic tools, all of which can be interpreted as representing sociotechnical regimes, have however been documented, such as nut cracking (Goren-Inbar et al. 2002) and butchering (e.g., Rabinovich et al. 2008). There is also evidence of woodworking (Goren-Inbar et al. 1992), which strongly suggests a general material processing use of basic lithic tools; this has also been verified for other Acheulean sites, such as in Schöningen ( 400 kya; Thieme 1997$)$ and Peninj ( 1.5 mya [million years ago]; Domínguez-Rodrigo et al. 2001). At Schöningen, wooden javelins were found along with cutting tools and retouching tools, indicating both the existence, connection, and something about the internal structures of three regimes: (i) a tool production regime, (ii) a higher level woodworking regime supported by the tool regime, and (iii) a big game hunting regime supported by the woodworking regime. Implied are, for example, raw material provision regimes and a carcass-processing regime.

The GBY site also provides early evidence of persistent domestication of fire (Goren-Inbar et al. 2004), predating widespread use by several hundred millennia (Roebroeks and Villa 2011; Rolland 2004). The same goes for the systematic use of fish as a source of nutrition, which is seen at the GBY site long before this becomes commonplace in the Upper Paleolithic. Fire use appears likely to have been a local major regime that was strongly linked to many other practices, while the exploitation of fish more likely represents a locally minor regime complementing more major subsistence strategies. Exceptions like these are the rule in the archaeological record. For instance, despite the strong emphasis on big game hunting during the MP, numerous examples exist of exploitation of small and hard-to-catch resources (see Gaudzinski-Windheuser and Niven 2009), which is not to speak of the MSA, which is replete with examples of local styles, ornaments, and technologies (McBrearty 2007; McBrearty and Brooks 2000). Although there are no particular reasons to believe that the GBY instances were ancestral to much later universalized regimes, they demonstrate the existence of developed practices that constitute minor regimes that could act as fodder for radical innovation.

\section{Early Human Sociotechnical Organization: Flexibility and Conservatism}

This case study will follow hominid organic and sociotechnical evolution through the emergence of a rudimentary hunter-gatherer lifestyle and the spread of erectoids across the Old World. The path that we have chosen through the thicket of archaeological and paleontological evidence (and their interpretations) is one that emphasizes the interplay between diet, physiology, ecology, and the generativity of modified lithic technology.

The emergence of the Oldowan around 2.6 mya (Semaw et al. 2003) and its spread across east and south Africa would be the first step toward establishing what we might call a human sociotechnical organization. But it is likely that the organization of the overall Oldowan sociotechnical system would still essentially be that of the great apes, with a set of quite separate regime systems rather than a hierarchy of regimes. The reason why this can be suspected is that butchering is the only verified use of Oldowan tools before the end of that period. This suggests that the full generativity of lithics (see the "Exaptive Bootstrapping" sec.) does not appear to have come into play yet at this point. While there exist indications of uses of lithics besides butchering in the early Oldowan (Beyries 1993), the evidence is tenuous (Domínguez-Rodrigo et al. 2005). So it appears likely that if such uses existed, they would have constituted minor regimespaving the way for, but not yet constituting, a more complex organization that lay ahead.

We propose that the human sociotechnical organization originated in the realization that lithics afforded manipulation of a wide range of materials besides animal carcasses. This general affordance provided exceptional leverage in terms of the range of implements that could be made (Davidson and McGrew 2005). This is an example of what we mean by a portal innovation: its generative effects on the sociotechnical system cannot have been part of the reason why it was initially adopted into a general role. Modified lithics would sneak in under and transform virtually all activity that relied on processed materials, and in the process it would also over time spawn new such activities that had previously been unthinkable; e.g., spears, hafted points, big game hunting, hide working. The scene was set for a major reorganization of the sociotechnical system: from something resembling the organization of great ape technology to a hierarchy with a strongly entrenched base and more and more flexible regimes upward.

Signs of such a shift appear toward the end of the Oldowan and the beginning of the Acheulean. The earliest direct sign is evidence found in late east African Oldowan tools (Beyries 1993; Keeley and Toth 1981) of the application of lithics to a wider variety of materials, and in Acheulean tools of similar age (Domínguez-Rodrigo et al. 2001). Another sign suggestive of an external innovation cycle is concurrent transformations involving physiology, cultural organization, and ecological interactions. The shift between $H$. habilis and $H$. ergaster brings many physiological changes, such as an increase in body mass, encephalization, a reduction in masticatory musculature and postcanine tooth size, and an adaptation to a more modern mobility pattern with an essentially modern postcranial anatomy and thermoregulation (Plummer 2004; Wood and Strait 2004). It also brings evidence of behavioral changes including food sharing, change in land use patterns, and in general the emergence of a rudimentary hunter-gatherer lifestyle (see, e.g., Snodgrass et al. 2009 for a review). The first hominids found outside of Africa (at Dmanisi, Georgia, 1.75 mya; Vekua et al. 2002) are also dated approximately to this period, and $H$. erectus is subsequently found all over the Old World in a wide 
range of biotopes. The thesis that a new sociotechnical organization can have emerged that provided key abilities from early on is buttressed (i) by the fact that Dmanisi tools are Oldowan in character rather than Acheulean, (ii) by the primitive physiology of the Dmanisi hominids (they were not fully developed erectoids; see Vekua et al. 2002), and (iii) by the low frequency of bifaces in east Asia and the generally low affinity to western Acheulean bifaces in those that have been found (Norton et al. 2006; Petraglia and Shipton 2008). This pattern would then be consistent with a migration initiated early during the external innovation cycle. The characteristic Acheulean bifaces would be an effect as much as a cause of this transition.

The early human sociotechnical organization certainly witnessed substantial flexibility relative to ecology and climate, but notably no trend toward diversification in resource exploitation. To the contrary, as mentioned in the Exaptive Bootstrapping section, the trend was toward narrowing and climbing higher in the trophic system, and the Neanderthals finally occupied a niche at the very top, typically specializing heavily on one or a few species (see, e.g., Gaudzinski 2006; Gaudzinski-Windheuser and Niven 2009; Kuhn and Stiner 2006; Stiner 2002). A logical development would be to follow the path of refining exploitation strategies for the best yielding resources that were already targeted and for which considerable sociotechnical adaptation had been achieved: that is, to move to larger game and toward being able to target them as efficiently as possible, that is, fat-rich prime adults rather than only young and infirm animals. The early modern sociotechnical organization would be hierarchical and exhibit a system of linked regimes, but they would primarily be subservient to an ever-narrowing set of top-level regimes by which the groups would live and die. Few of these, perhaps (at least locally) only one, would be directed at obtaining food. The sociotechnical system developed to maximize output and minimize risk, but it did so path-dependently and constrained by its own organization. The sociotechnical organization of the UP/LSA, which we might have called the modern human sociotechnical organization if we were to deal with it here, would be tempting to characterize as a break with the pattern of homing in more and more closely on bigger and bigger prey to that of being able to home in on several targets at the same time and to be able to swiftly change targets as needed. This is clearly not possible to achieve by the incremental improvement of a big game hunting regime, and reliance on such a regime must have been exceptionally hard to break out of. Everything from technology to hunting practices, dwelling places, group structure and size, social interaction strategies (within and between groups), and conceptions of value and identity would be coadapted to the occupation of this niche and contribute to a powerful lockin.
Entrenchment, Entanglement, Hierarchy, and Lock-In

\section{Archaeological Homogeneity}

Taphonomic processes have left us almost exclusively with two inert parts of ancient hominids to pore over: their skeletons and their small lithic technology. But if lithic technology mainly, and in particular early on, belonged to basic and strongly entrenched regimes, such a bias could play tremendous tricks on us today. Adaptability and inventiveness would largely be archaeologically invisible, and rare signs of behavioral complexity beyond what is evidenced by lithics would seem either paradoxical or too fantastic to even consider seriously. ${ }^{7}$ It would only be at the rare points in time when innovation affected the lithic core technology that clearly detectable traces of sociotechnical change would be left behind. During the prolonged periods of deep lock-in, lithics would remain relatively static, and the archaeological record will be uneventful and uniform despite considerable climatic and ecological variations across time and space (see, e.g., BocquetAppel and Tuffreau 2009; Foley and Lahr 2003; Kuhn and Stiner 2001; Stout et al. 2010). Most lithic technology may simply not have been in direct contact with geographically and temporally variable parts of the environment but have interacted on the basic level of materials such as meat, wood, straw, hides, bone, antler, and so on. Inferring cultural stasis and homogeneity on the basis of stasis and homogeneity in lithics could in other words be akin to arguing that mice and elephants must be similar because of a high similarity on the cellular level-we would compare them on a level that is strongly generatively entrenched and that simply is not the main locus of variability. Indeed, with respect to raw material availability, a point at which lithic skills were strongly and directly exposed to environmental variability, considerable variation does occur over time and space (see Kuhn and Stiner 2001).

\section{Regime Change: Adaptation and Revolution}

Due to functional entanglement and specialization, regimes cannot easily undergo radical innovation even when put under substantial pressure. This pressure, however, may open the door for the replacement of one regime by another regime (see "The Multilevel Perspective" sec.). At the rare points when this successfully took place in the lower parts of the sociotechnical system, cascading (see the "Exaptive Bootstrapping" sec.) reconfiguration could lead to revolutionary change; when it occurred in the upper parts, the overall system would be less disturbed. The multilevel perspective cites two main preconditions for regime replacement: (i) a window of opportunity whereby one or more regimes begin to fit in poorly and (ii) readily deployable alternatives to such regimes,

7. For example, seafaring H. erectus (Bednarik 2003, 2011). 
that is, minor regimes. If either of these two preconditions is lacking, status quo will remain (e.g., Geels and Schot 2007).

The basic mechanics of window-of-opportunity formation can be summarized as follows. Stress builds up as sociotechnical regimes strive to configure themselves to match the external environment, horizontally between the regimes, and vertically to the locked-in core parts of the system. Over time, stress may reach a point where internal adaptation between parts of the system begins to lag considerably. Strong selection pressures and new affordances will come to persist without being effectively pursued, and regimes will find it increasingly hard to accommodate needed changes. The internal fitness that a major regime enjoys as a central and well-integrated part of the sociocultural system will be diminished, and we may speak of a window of opportunity opening up since external selection pressures now have stronger relative importance.

The most common type of window was probably due to changes in the relative availability of resources. We expect that the sociotechnical system was adapted to deal expediently precisely with that sort of change through superficial reconfigurations. But over longer time scales, drawn-out directional climatic change occurred, not least due to glaciation cycles, and substantial organic evolution unfolded. This could slowly open up deep rifts in the sociotechnical system, beyond what could be dealt with by superficial reorganization. As stress increased, windows would open up more and more frequently and widely, with deeper and more frequent reorganizations leaving detectable but still isolated and recursive archaeological traces behind. Then, eventually, a deep radical innovation would turn out to be a portal innovation and come to sweep the board. This would be what we now detect as a shift between the major technological modes.

As suggested in the Archaeological Homogeneity section, radical innovation seems not to have been the weapon of choice for adaptation. The entrenched core regimes would instead have been under pressure to undergo incremental innovation to become as configurable as possible so as to make the top tiers more flexible and thereby reduce the need to change the core. What were the evolutionary dynamics of core regimes? Delagnes and Meignen (2006), for example, trace the fate of different debitage methods (Levallois, discoidal, and Quina) across the MP in France, and although the Quina method appears late, the pattern conforms well to what Kuhn (2006) finds in a similar study of the Italian MP, namely that "flexibility seems to have been manifest mainly through redeploying and recombining a limited range of technological options, not as the development of entirely new technological solutions." Kuhn $(2006,116)$ furthermore notes that whatever temporal trajectories can be discerned are in any event not in the direction of the UP.

The top of the hierarchy was the organ of external adaptation in the sociotechnical system, and most regime shifts would thereby be superficial and quite uneventful. Regime replacement, we hold, is realistic only if a suitable regime that could be redirected without too much deep modification already existed. Developing a functional regime from scratch under pressure would probably have had a very low likelihood of success: such a regime would be unrefined, as it would not represent accumulated time-tested knowledge, and those forced to begin practicing it would not be highly skilled. The presence of minor regimes was therefore likely to be highly important for adaptability, and mobility was probably the main strategy before sociotechnical flexibility became highly developed. As an entirely conjectural example (along with those in the sec. "The Synthetic Model in Context"), imagine that the bow and arrow emerged as a toy for children, or perhaps a display weapon, and underwent a good deal of functional refinement in that role, that is, that it was turned into a functioning but minor regime with practices, materials, and production routines worked out. Then, if one day conditions called for a broadening or alteration of the subsistence base, this technology would be available as an option and would not need to be conceived ex nihilo. With respect to minor niches, complexity breeds complexity: the larger and more diversified the culture, the more nooks and crannies will there be in which such alternative ways of doing things can thrive without being dominant.

\section{Summary}

In evolutionary biology, developmental models scaffold natural selection into a richer system of processes that arise from the organization that evolution itself brings about. Natural selection is seen as necessary but not sufficient for understanding the patterns of evolution. We have argued that the corresponding move should be made in the study of cultural evolution. To this end, we introduced a provisional synthetic theory where three components from innovation researchwhich is an area where sociotechnical organization and process have lately been studied extensively-were brought together under a more overarching logic borrowed from evolutionary developmental models from biology. The intention was to demonstrate that a theory tailor-made for the purposes can be developed. In some cases, concepts were immediately useful, but in other cases they must be customized, abstracted, and reapplied, and several "bridging concepts" had to be introduced.

The result should not be viewed as a ready and delivered framework, and the case studies should not be seen as its definite explanations and predictions. It should be viewed as a demonstration of a possibility and a starting point that is sufficiently developed to provide leads for further exploration.

We think that a suggestive picture of the evolutionary development of culture emerges as a result of this exercise, if so only in outline. Unless earlier hominid culture operated on radically different principles than that of more recent societies - and there are no reasons to believe that they didwe have strong reasons to believe that such cultures came to be organized hierarchically, with interlinked but compart- 
mentalized and specialized regimes, subject to strong conservatism at the base and successively more flexibility toward the top.

We furthermore think that this organization was far more than just an adaptation to an environment: it opened up a whole universe of new possibilities for the future. The emergence of such an organization, which we have here suggested can have occurred at the Oldowan-Acheulean transition, could even be seen as a cultural version of the Cambrian Explosion and the emergence of multicellularity in the biological world. It also suggests a candidate differentiation between human culture from animal culture on the basis of organization.

We hypothesized that modified lithic technology would have played a crucial role in this development by establishing itself as the enabler and precondition-directly or indirectlyfor just about all hominid cultural activities. By serving general material processing roles, it made secondary implements and strategies possible, and these would form the upper tiers of this hierarchy. With lithics entrenched at the base of the sociotechnical system - analogous to cells in multicellular organisms-they would not need to change very much. Their main design criterion would be to make change possible in the upper tiers. In other words, they would be adapted to allow flexibility, and we should not be surprised if they themselves were quite inert in the face of ecological heterogeneity. The normal mode of change in response to ecological heterogeneity would instead have been superficial reconfigurations in the upper levels of the sociotechnical system, and the system as a whole would be adapted to allow such flexibility. The mode of sociotechnical change over time would be characterized by lock-ins and bootstrapping processes: phenomena that we cannot even begin to consider unless we apply an evolutionary developmental perspective.

But due to changes in systems external to culture-not least physiological evolution and changes in ecology and climate-change also in the more fundamental parts of the sociotechnical system would be inevitable sooner or later. When such change did happen, it probably occurred in geographical areas where the environmental conditions were such that the threshold to such change locally happened to be lower. Once the lock-in was broken, we identified what was referred to as an external innovation cycle as a particularly important type of change process. The external innovation cycle is related to a lock-in roughly the way that positive self-reinforcement is related to negative self-reinforcement: it is basically the same mechanism operating in a different dynamical regime, and both are due to the nonlinearity of evolutionary processes. This innovation process is inspired by the logic of niche construction theory whereby also systems external to culture are brought along in the change process: cultural change comes to generate ever-new basic conditions for more change and at the same time block the path backward. Most importantly, physiological evolution (e.g., cognitive evolution) and the destruction/construction of ecological niches could create such ratchet effects. Once such a process was set off, it could perpetuate itself without the need for external driving forces, just like a lock-in can maintain itself despite external driving forces.

\section{Acknowledgments}

We wish to acknowledge the support of the EU-FET grants MD (no. 284625) and INSITE (no. 271574). We also wish to thank David Lane, Steven Kuhn, and Mary Stiner for valuable discussions and feedback on these topics and on draft versions of this paper.

\section{Comments}

\section{Iain Davidson}

Emeritus Professor, University of New England, 10 Cluny Road, Armidale, NSW 2350, Australia (iain.davidson@live.com.au). 28 VI 13

This is a bold attempt by nonarchaeologists to shift the nature of the debate about cultural evolution using some theoretical insights developed in evolutionary biology and industrial systems theory. The work is grounded in some insights into early archaeological evidence-though not without relying on some false friends along the way. Arguably, even more insight could be gained by an even more penetrating analysis of the elements of the archaeological story - but maybe that was not necessary here.

I am delighted that one feature of their argument arises from my paper with McGrew about the new niche constructed from the incidental abandonment of stone flakes and cores from the very beginning of stone toolmaking. Absent from our paper, and theirs, is any real understanding of how long it took for hominins to move from constructing the niche to occupying it. Important progress on this problem has been made by Matt Pope and Adam Brumm (personal communication, 2012 $)^{8}$ observing the incidence of bifacial cores reused after abandonment for a period long enough for them to become patinated.

The authors point to the power of amplification of "small events into landslides," a process that Noble and I (e.g., Noble and Davidson 1996) repeatedly pointed out as a recurrent process in human evolution, but their view of it would have been enhanced by placing more emphasis on the occurrence of variation and the operation of selection on new variants. It is my belief that the major building blocks and classifications on which archaeology has relied since the nineteenth century are not a good starting point for that sort of analysis. It would be nice to see a few more examples of the small

8. The editors of this journal may care to note that Pope and Brumm's important paper was rejected from Current Anthropology. 
things that turned into landslides: my favorites are the planoconvex cores from Olduvai DK (Leakey 1971) or Peninj (de la Torre et al. 2003) that could be rejuvenated and become Levallois cores, and the fact that the intensification of the exploitation of gazelles in the Natufian was followed by the domestication of goats, which had been a minor element of the faunal exploitation previously (see data in, e.g., Munro 2004).

It is, therefore, paradoxical that the authors rely on GBY and the claim that its archaeology results from a single culture that lasted 50,000 years-longer than the whole time modern humans have been the dominant species on the planet. But the essence of culture is that it is transmitted from cultureholders to the culturally naive and that in that process of teaching and learning there is ample opportunity for what Henrich (2004) described as failure in cultural copying. Here, I think, the explanation lies in a little-emphasized aspect of the, surely inappropriate, comparison with toolmaking in modern Papua New Guinea: the raw material is described as hard-to-process basalt. Here then is a context in which equifinality might arise from the limited ways in which the raw material can be worked-hence the uniformity may not be due to inexplicably perfect and long-lasting cultural transmission but a convergence on a method that works, perhaps on many discrete occasions, including ultimately recent Papua New Guinea. The attempted analogy actually works the other way around.

\section{Erella Hovers and Anna Belfer-Cohen}

Institute of Archaeology, The Hebrew University of Jerusalem, Jerusalem 91905, Israel (hovers@mscc.huji.ac.il, belferac@mscc.huji .ac.il). 13 VI 13

Archaeology is notorious for being an empirical discipline that borrows from many other, theory-driven branches of research. We do not often see the archaeological record-a proxy for cultural evolution (albeit a partial one, as stated correctly by the authors) - being investigated by experts from other disciplines, whose ambition is to offer "a starting point ... an argumentation and demonstration" for a new developmental approach to sociotechnical evolution. By the authors' own admission, the formal approach advocated here borrows elements from evolutionary, optimal foraging, and general systems theories, as well as the recently developed theory of niche construction, in order to make sense of Paleolithic culture. It is precisely because archaeologists are compulsive borrowers of theories (e.g., Binford 2001) that much of this new offering had already been embraced, for better or worse, by prehistorians.

The advocated approach attempts to account for gene-culture-environment interfaces, but it fails to consider how particular cultural histories influence group and individual decision making when interacting with their environment (physical and social) at a given time. The authors claim that a powerful sociotechnical lock-in, the emphasis on meat eating, had been operating and growing stronger from the Oldowan to the Middle Paleolithic Neanderthals-perceived as committed to carnivory. This time-transgressive intensification directed cultural evolution in all its aspects. Thus, lithics "evolved" mainly to accommodate the drive of getting more meat in a more efficient way. The authors consider the MPUP transition as a break with the constriction imposed by homing in more and more closely on bigger and bigger prey, and the appearance of behavioral flexibility.

This scenario is inconsistent with the archeological data throughout the relevant time span. The Oldowan technosystem is potentially the only aspect of the Oldowan that differs from the great apes. Still, the invention of Oldowan stone flaking is built on behaviors known among apes (Hovers 2012; Read and van der Leeuw 2008). It is for this reason that we disagree with the statement that Oldowan stone tools respond to meat-processing needs and are associated strictly with butchering. Great ape tool use does not encompass butchering (and in fact does not include intentional stone flaking in the wild; McGrew 2010). Moreover, isotopic, tooth microwear, and tooth calculus findings indicate that the diet of hominins from the Oldowan through the Middle Paleolithic (as well as later) was variegated, regionally diverse, and far from portraying the strong commitment to meat eating envisioned by the authors (Cerling et al. 2013; El Zaatari et al. 2011; Henry, Brooks, and Piperno 2011; Hockett 2012; Speth 2010; Ungar and Sponheimer 2011; Ungar 2012).

Finds from the Acheulian site at GBY indeed speak to developed cultural practices of early hominins. We concur that such finds need not necessarily be considered as ancestral to much later universalized regimes. Indeed, such finds may evidence the now widely accepted concept that even major inventions might have disappeared and reappeared as part of the multitude of processes that constitute the "evolution of culture" (e.g., Henrich 2004; Hovers and Belfer-Cohen 2006; Powell, Shennan, and Thomas 2009; Premo and Kuhn 2010; Shennan 2001). How, then, could they serve as "fodder for radical innovation" in much later times? Implicit in the authors' statement is an entrenched belief in linearity, contrary to the main trust of their approach. Their statement also disregards the role of historical trajectories (e.g., context of cultural transmission, demographics) that are proximal triggers for the emergence and diversity of prehistoric cultural innovations and institutions.

As archaeologists trained in lithic analysis, we are the first to recognize the importance of lithic technology in understanding cultural evolution. Still, this is a far cry from the reductive statement that lithic technology is "the enabler and precondition ... for just about all hominid cultural activities," a prime mover of all things. Perceiving of lithics as analogous to cells in multicellular organisms defines culture and its products as just another biological organ. Biological evolution has an important role in shaping the human condition, but only 
up to a point. Culture, including its material manifestations, cannot be explained through biological models except on a very abstract level of discourse. This is probably because one has to take into consideration the fact that as complexity rises, it can change the rules of the game. "Culture" made humans "too clever by half" in the sense that our species acts contra its biological "good" (Dawkins 1989).

Andersson, Törnberg, and Törnberg made a commendable endeavor to test a theoretical model through archaeological case studies, yet it results in a "just so story." In spite of the emphasis on flexibility and connectivity of cultural processes and structures, the suggested model is rigid when it comes to explaining the processes inferred from the archaeological record. The authors came up with a typology of processes rather than explanatory insights. What is sorely needed is a middle-range theory that will bridge between valued theories of complex systems on the one hand, the empirical archaeological data on the other, and the historical circumstances that are responsible for cultural evolution.

\section{Timothy A. Kohler}

Department of Anthropology, Washington State University, Pullman, Washington 99164-4910, U.S.A. (tako@wsu.edu). 19 VI 13

Andersson and colleagues offer a set of stimulating and valuable suggestions for archaeologists seeking to explain innovation in the archaeological record from an evolutionary perspective. ${ }^{9}$ I also appreciate their general argument that cultural evolution ordinarily interacts significantly with development (the "evo-devo" perspective) and should be analyzed in that way.

It seems to me, however, that their account misunderstands some aspects of current and recent directions by archaeologists employing evolutionary processes in an explanatory fashion. These directions have developed largely in the AngloAmerican literature, drawing inspiration primarily from biology and population genetics, whereas the approach taken by Andersson et al. seems to stem ultimately from a systems dynamical approach best exemplified, in recent archaeology, by several of the contributions to van der Leeuw and McGlade (1997). Such approaches, in general, draw inspiration from the nonlinear dynamics of physical systems and therefore have trouble representing the population thinking that dominates current evolutionary approaches in archaeology.

In my view, Andersson and colleagues get off somewhat on the wrong foot by contrasting explanations derived from evolutionary biology (their PA) with those provided by a particular approach to cultural evolution that they call the ecological/economical approach (EA). This contrast in itself is fine, but there seems to be little recognition that their EA is

9. Coincidentally, I have recently argued for incorporating some of these same perspectives in complex-systems approaches to archaeology (Kohler 2012:105-106). only one possible way of applying evolutionary logic to the analysis of cultural evolution. This in turn leads them to suggest that evolutionary thinking by (Paleolithic) archaeologists "share[s] a common neo-Darwinian model of adaptation where natural selection is seen as the sole provider of evolutionary direction." If this statement is meant to represent evolutionary thinking in archaeology more broadly, it is at best only partially true.

Currently there are two major and not entirely independent ways of approaching cultural evolution in archaeology (Shennan 2012). One is indeed EA, which its proponents more often call human behavioral ecology. The other, with foundational texts by Cavalli-Sforza and Feldman (1981) and Boyd and Richerson (1985), can be called dual inheritance theory (DIT). This approach analyzes the transmission and relative success of cultural variants as an inheritance system that is linked to, but partially independent of, an underlying system of genetic inheritance acting on the carriers of those cultural traits. The logic of this approach is relevant here since the partial independence of this trait transmission system allows for neutral (with respect to selection) and even maladaptive traits to proliferate under certain circumstances. Thus, the framework already set up by DIT explicitly deals with "how culture is organized, how it develops, and how it interacts with other processes in the neo-Darwinian framework" claimed by Andersson et al. to be lacking in an evolutionary archaeology that is in their view guided by a too-facile devotion to an underlying model of adaptation. In the interests of nonproliferation of theoretical constructs, Andersson et al. might have considered developing their ideas within the context provided by DIT. At a minimum, they should give clear reasons for not doing so.

On a more positive side, I was pleased to see attention given to clarifying the terms of the comparison being made between evo-devo approaches in biological and in cultural evolution. In biology, evo-devo approaches examine how mechanisms affecting the development of the phenotypes of individuals (through the interaction of their genotypes and an environment) channel or bias the long-run evolution of the population. How should we map these terms into cultural evolution? Mesoudi et al. (2006:367) suggest that one approach (among several) would be to consider semantic information in brains or external storage devices (e.g., parietal art) to be "like" the genotype and the eventual expression of such acquired information (through behavior, language, artifacts, etc.) in some environment to be "like" the phenotype. Then "cultural evo-devo" would study how the interaction between semantic information and the natural and social environment shapes behaviors and artifacts and ultimately, at the population level, the cultural evolutionary trajectory. As in DIT approaches, the focus here is on the transmitted information. This in fact seems to be the approach taken here as well: "Ideas, cultural representations, memes, routines, or whatever we want to call them here, play a role roughly analogous to genes." 
As Andersson et al. continue to develop these ideas, I would urge them to better integrate their perspectives with existing approaches to evolutionary archaeology and to be more aware of intellectual antecedents (e.g., does Flannery's [1968] attention to feedback processes not invalidate their claim to have discovered in feedback relations "entirely new types of explanations for the evolution of cultures"?); to be more explicit about the structures of the populations being discussed (e.g., are intergroup competition and cultural group selection the likely motor for the innovations they seek to understand?); and to consider the implications of their arguments for the study of causation in evolving sociotechnical systems (see, e.g., Laland et al. 2011 on the necessity of employing reciprocal causation to understand the behavior of such systems, providing a logical underpinning for employment of concepts such as niche construction theory).

\section{Manfred D. Laubichler}

School of Life Sciences, Arizona State University; P.O. Box 4501, Tempe, Arizona 85287-4501, U.S.A. (Manfred.laubichler@asu.edu). 6 VII 13

Claes Andersson and his coauthors argue that traditional models of cultural evolution need to be expanded to include elements of "evolutionary developmental theories" in order to overcome the limitations of what they perceive as simplistic applications of external selective dynamics in our understanding of cultural and technological evolution. They take their inspiration from similar debates within evolutionary biology that have, over the last 3 decades, led to an expansion and transformation of evolutionary theory. As a result, parts of evolutionary theory-the newly emerging fields of developmental evolution and evolutionary developmental biology (evo-devo), two conceptually distinct, albeit related approaches-are now also focused on the origin of variation as a distinct explanatory problem, one that requires understanding the mechanisms of individual development as part of any explanation of evolution.

One of the central questions for developmental evolution has been the problem of innovation. In evolutionary biology, innovation mostly refers to novel phenotypes, often those connected to body plan evolution, that are not simply variations of already existing characters. The main challenge has been to explain such phenotypic innovations in light of highly conserved genes and especially gene numbers. Simply put, comparative genomics has falsified the deceptively elegant assumption that new phenotypic characters are simply the product of new genes (remnants of this view are still widespread in form of the "gene for" ideology). The answer to the problem of innovation is now found within the complex regulatory architecture of the genome and its role in mechanistically explaining development. In most basic terms, increasing evidence suggests that (often small) changes in underlying gene regulatory networks can explain the emergence of new characters (innovations), while redundancy in and conservation of specific parts of these networks at the same time explains the long-term stability of other phenotypic features, such as body plans.

Current developmental evolution has a well-developed research program for studying phenotypic innovations, or more precisely, inventions. Taking a lead from the economic theory of innovation, developmental evolutionists have also adopted Schumpeter's distinction between invention and innovation, where invention refers to the developmental origin of a novel phenotype, whereas innovations are those inventions that successfully spread though populations and leave a phylogenetic signal. The latter then connect considerations of internal developmental mechanisms related to the origin of (novel) variation with the external dynamics of natural selection.

But in the case of innovations or evolutionary novelties, these external dynamics are not simply those of natural selection. An innovation or a novel phenotypic character by definition opens up a new niche or changes the dimensionality of existing niches. Therefore, the new evolutionary theory of innovation combines developmental mechanisms that can explain the origin of inventions with those processes that describe the constructive interactions of organisms with their environment and with each other (niche construction, natural selection).

As this brief overview of trends in current evolutionary theory shows, Andersson et al.'s approach is grounded in a broader framework of theoretical approaches that aim to understand innovation from a complex adaptive systems perspective. Their paper thus points to a larger theoretical question: Is it possible to develop a unified theory of innovation across domains that is based on insights derived from perspectives of developmental evolution, niche construction, and complex adaptive systems?

In my view there is reason to be optimistic, but we have a long way to go. Studies like Andersson et al.'s that try to frame case studies about lithic technology within the context of developmental evolution models, such as the external innovation cycle of cultural evolution, reveal the usefulness of these novel perspectives beyond the narrow domain of rewiring gene regulatory networks and phenotypic evolution. Research that analyzes patent data, institutional diversity, the development and evolution of cities, or the dynamics of knowledge systems all point in the same direction, namely that innovation can be defined as specific shifts in the state space of complex systems at the intersection of internal regulatory and external dynamics.

So where does this leave us? For once, this initial definition of innovation is very abstract. Therefore, we need more empirical case studies so that we can see to what degree innovation dynamics are similar and different within and across domains. Based on these descriptive cases, we also need to build predictive models that can be tested. It is one thing to frame cases of innovation within a specific theoretical point 
of view, such as developmental evolution or niche construction. But if we want to make real progress in understanding innovation dynamics across scales, we need to have testable hypotheses. Population biology and economical theory have developed such models for the dynamics of variants within populations; now we need to build similar models for the origin of novelty and innovation. This paper is a step in that direction.

\section{Michael J. O’Brien and Stephen J. Lycett}

Department of Anthropology, University of Missouri, 317 Lowry Hall, Columbia, Missouri 65211, U.S.A./Department of Anthropology, University of Kent, Marlowe Building, Canterbury, Kent CT2 7NR, United Kingdom (S.J.Lycett@kent.ac.uk). 3 VI 13

Cross-disciplinary endeavors such as the one reported here are to be applauded, but there is of course inherent risk, especially if one is entering somewhat unfamiliar territory. This is where we see Anderson and colleagues, who, in an effort to promote their evolutionary developmental approach to cultural evolution, have either overlooked or ignored an enormous body of literature that already views culture in the way they suggest: as a system of descent with modification mediated by the pillars of inheritance, variation, and sorting. This oversight has led them to build a straw man and to unknowingly reinvent a first-generation cultural evolutionary wheel.

The authors, for example, are nowhere near the first behavioral scientists to examine culture from an "evo-devo" perspective (e.g., Mesoudi and O’Brien 2008; O’Brien et al. 2010), and although they mention in passing niche construction theory (NCT), they apparently are unfamiliar with the literally dozens of articles and journal issues devoted to NCT and culture (e.g., Kendal, Tehrani, and Odling-Smee 2011; Laland, Odling-Smee, and Myles 2010; O'Brien and Laland 2012). The myriad issues covered there are critical for the kind of argument Andersson and colleagues are trying to make: that, as Lewontin (1983:280) famously put it, "organisms do not adapt to their environments; they construct them out of the bits and pieces of the external world."

Unfamiliarity with the literature, both biological and cultural, leads Andersson and colleagues to state that in evolutionary biology, "Natural selection is seen as necessary but not sufficient for understanding the patterns of evolution. We have argued that the corresponding move should be made in the study of cultural evolution." We have two comments. First, in evolutionary biology, natural selection is not seen as necessary. Rather, what is necessary is a mechanism that sorts among variants. That mechanism could be, and often is, selection, but it could also be stochastic sorting, or drift, which is perfectly capable of "causing" evolution. Second, decades of work on cultural evolution stemming from the efforts of Cavalli-Sforza and Feldman (1981) and Boyd and Richerson
(1985), among others, have taken account of not only the important role played by stochastic sorting but myriad other aspects of a Darwinian cultural evolution. Importantly, cultural evolution is not merely an analogy to, or metaphor for, biological descent with modification but rather an evolutionary process mediated by variation, inheritance, and sorting (Lycett 2011).

Of significance in the context of Andersson and colleagues' discussion, archaeological studies have been at the forefront of much of this work (e.g., Bettinger and Eerkens 1999; Eerkens and Lipo 2005; Lyman and O’Brien 1998; Mesoudi and O’Brien 2009; Neiman 1995; O’Brien and Lyman 2000, 2002; Shennan 2002), including those studies dealing specifically with issues of variation within entities such as "Acheulean" (e.g., Kempe, Lycett, and Mesoudi 2012; Lycett 2008, 2011), which is the subject of Andersson and colleagues' case studies. Curiously, the authors cite several papers by Steven Kuhn, and even thank him for "valuable discussions and feedback," but they ignore his insightful paper "Evolutionary Perspectives on Technology and Technological Change" (Kuhn 2004).

Returning to the authors' claim that selection is the only visible process in cultural evolutionary research, they note that the two dominant approaches to the study of Paleolithic culture-one ecological/economic and the other physiological- "share a common neo-Darwinian model of adaptation where natural selection is seen as the sole provider of evolutionary direction." This simply is untrue, whether the subject is the Old World Paleolithic or the New World Paleolithic. If it were, why do we find articles with titles such as "An Experimental Test of the Accumulated Copying Error Model of Cultural Mutation for Acheulean Handaxe Size" (Kempe, Lycett, and Mesoudi 2012) or "Acheulean Variation and Selection: Does Handaxe Symmetry Fit Neutral Expectations?" (Lycett 2008) or "The Accumulation of Stochastic Copying Errors Causes Drift in Culturally Transmitted Technologies: Quantifying Clovis Evolutionary Dynamics" (Hamilton and Buchanan 2009)?

The last title brings us to a critical component that is all but missing from Andersson and colleagues' discussion, namely, cultural transmission, which is the vehicle of cultural inheritance. Ignoring the vast literature on transmission allows the authors to state that culture is "notably absent from the stage as a factor in its own evolution; there is no room for explanations having to do with how culture is organized, how it develops, and how it interacts with other processes in the neo-Darwinian framework." Again, this is an untrue and naive statement. The authors might look, for example, at work on the organization and evolution of cumulative culture (e.g., Enquist, Ghirlanda, and Eriksson 2011; Tomasello 1999). And, even a cursory glance at any of the many works on NCT and culture will completely undermine the notion that culture is "notably absent from the stage as a factor in its own evolution." 
Table 1. Expansion and extension of the Darwinian model

\begin{tabular}{|c|c|c|c|}
\hline $\begin{array}{l}\text { Darwinian model } \\
\text { (1) }\end{array}$ & $\begin{array}{l}\text { Modern synthesis } \\
\text { (2) }\end{array}$ & $\begin{array}{l}\text { Expanded synthesis } \\
\text { (3) }\end{array}$ & $\begin{array}{l}\text { Social/cultural extended synthesis } \\
\text { (4) }\end{array}$ \\
\hline $\begin{array}{l}\text { Variation } \\
\text { Inheritance } \\
\text { Natural selection }\end{array}$ & $\begin{array}{l}\text { Gene mutation } \\
\text { Mendelian inheritance } \\
\text { Population genetics } \\
\text { Contingency } \\
\text { Speciation and trends }\end{array}$ & $\begin{array}{l}\text { Evo-devo theory } \\
\text { Plasticity and accommodation } \\
\text { Niche construction } \\
\text { Epigenetic inheritance } \\
\text { Replicator theory } \\
\text { Evolvability } \\
\text { Multilevel selection } \\
\text { Genomic evolution } \\
\text { Imitation/phenotypic inheritance } \\
\text { Social cognition }^{\mathrm{a}} \\
\text { Social behavior }^{\mathrm{a}}\end{array}$ & $\begin{array}{l}\text { Cultural idea systems } \\
\text { Language and other symbolic forms of communication } \\
\text { Generative grammars } \\
\text { Enculturation } \\
\text { Cultural models } \\
\text { Intentionality and purposeful behavior } \\
\text { Recursive reasoning } \\
\text { Theory of mind } \\
\text { Technological systems } \\
\text { Role systems } \\
\text { Organization systems } \\
\text { Symbolic inheritance } \\
\text { Invention and innovation } \\
\text { Social boundary }\end{array}$ \\
\hline
\end{tabular}

Note. Cols. 1-3: derived from figure 1.1 in Pigliucci and Müller (2010a). Col. 4: proposed extension addressing cultural and social evolution.

a Additions to Pigliucci and Müller's expanded synthesis.

\section{Dwight W. Read}

Department of Anthropology and Department of Statistics, University of California, Los Angeles, California 90095, U.S.A.

(dread@anthro.ucla.edu).6 VI 13

The authors credibly integrate some of the new ideas of the expanded synthesis of evolutionary theory (Pigliucci and Müller 2010b)—ideas that have expanded the modern synthesis (Mayr and Provine 1980; table 1, cols. 1-3) —into a developmental approach for explicating cultural evolution. Relevant to their argument, the expanded synthesis can be extended to encompass ideas relating to the evolution of social/cultural systems (table 1, col. 4).

Whereas the modern synthesis focused primarily on gene evolution through mutation, inheritance, and natural selection, the expanded synthesis has focused on endogenous processes affecting the development and expression of traits, not just their selection as optimal solutions to externally imposed change. The authors suggest that accounts of cultural evolution should focus similarly on endogenous processes relating to the development and formation of cultural phenomena. The goal is laudable; the means proposed for doing so are incomplete.

The authors identify several processes central to the evolution story applied to culture: the internal innovation cycle, exaptive bootstrapping, the external innovation cycle, generative entrenchment, and a multilevel perspective. As the authors note, none is specific to cultural evolution. Though these provide a richer and more complete picture of the evolutionary process than is obtained through focusing on traits and trait selection alone, still unanswered is a fundamental question: Why did the trajectory leading to Homo diverge radically from the trajectory leading to Pan, despite both trajectories having the same beginning point? Some have argued incorrectly that cultural evolution defined as an extension of biological evolution by including nongenetic traits transmit- ted socially and having an impact on behavior makes the difference.

The cultural side of Homo sapiens, though, is not determined through social transmission. As the authors comment, in the neo-Darwinian framework there is "no room for explanations having to do with how culture is organized, how it develops, and how it interacts with other processes" (see also Lane et al. 2009; Wimsatt and Griesemer 2007). Lacking is a critical innovation transformation introduced during hominin evolution that fundamentally redefined what constitutes the evolutionary process with regard to the cultural side of Homo sapiens (Read 2012; Read et al. 2009). The transformation changed innovation from an externally exogenous random mutation process to "innovation that allows for organizational change through endogenous processes acting on an assessment of current organizational functionalities [that] . . . did take place during hominin evolution" (Read et al. 2009:44). This "innovation innovation" (Read et al. 2009) reversed the previous pattern of functionality at the group level emerging from functionality at the individual level, to functionality at the individual level being derived from functionality introduced at the group level.

We can see the reversal in the development during the Upper Paleolithic of "an external cognitive architecture by which hominins achieved social extension within local groups and a wider community" (Gamble 2010:32), thereby transcending individually framed, cognitive abilities through group-level organization of individual cognitive abilities. The "cognitive architecture" enabling this social extension derives from the "culturally constructed systems of kinship [that] provide the basis for all the other culturally based forms of social organization that arose with modern Homo sapiens" (Leaf and Read 2012:19). Culturally constructed kinship systems whose organization is expressed linguistically through a kinship terminology enabled social relations to be extended 
in time and space beyond the local group, and the boundary of a community was thereby no longer limited by the scope of face-to-face interaction, as is the case with the nonhuman primates (Read 2012). Instead, the social system was transformed into a relation-based form of social organization expressed linguistically through a kinship terminology system (Read 2012). The culturally defined kinship terminology system provides the foundation for the social organization of hunter-gatherer societies from which more extensive forms of social organization have evolved.

The kinship terminology system neither emerges from patterned behavior of individuals (Leaf and Read 2012:16) nor provides functionality except through the group level: individually knowing a kinship terminology provides no functionality to that individual. Instead, functionality for the individual arises from a group collectively having and sharing a kinship terminology system, thus reversing the sequence for the expression of functionality implied by neo-Darwinian evolution. As a consequence, the social boundary for small-scale societies is determined by those who can mutually determine they are kin, using the kinship terminology as a symbolic computational system (Read 2001, 2007); hence the boundary became the consequence of an internal, rather than an external, process, in the manner discussed by the authors. The reversal in the expression of functionality implies that cultural evolution is not derived from evolution of individual traits, genetic or otherwise, but from evolutionary processes acting on the structure and organization of cultural idea systems (Leaf and Read 2012:14).

\section{Peter J. Richerson and Robert L. Bettinger}

Department of Anthropology / Department of Environmental Science and Policy, 1 Shields Avenue, University of California, Davis, California 95616, U.S.A. (rlbettinger@ucdavis.edu) 1 VII 13

\section{A Story Better Told Elsewhere}

Andersson et al.'s critique of what they call the ecological/ economic and physiological approaches to Paleolithic culture are well taken. In the case of humans, understanding our past certainly depends upon an evolutionary theory of culture, as they argue. However, they seem unaware of a large literature on cultural evolution and gene culture coevolution making the same point. It goes back to papers in the 1950s and 1960s (Alchian 1950; Campbell 1960; Gerard, Rapoport, and Kluckhohn 1956). Mathematical modeling of the processes of cultural evolution and gene-culture coevolution began in the 1970s, and major synthetic work was published in the 1980s (Boyd and Richerson 1985; Cavalli-Sforza and Feldman 1981; Lumsden and Wilson 1981). For a recent book-length review of the current state of the field, see Mesoudi (2011). Archaeologists and paleoanthropologists have been significant contributors (e.g., Bettinger 1991; Eerkens and Lipo 2005; Powell,
Shennan, and Thomas 2009; Shennan 2002; Tostevin 2013). The ability of geneticists to understand something of our evolutionary and demographic history has turned up many genes that are candidates to have been involved in episodes of culture-led gene-culture coevolution (Laland, OdlingSmee, and Myles 2010; Richerson and Boyd 2010).

\section{Reply}

We wish to thank the commenters for their valuable feedback and hope that in this brief response we will be able to clarify at least some of the issues that were raised. In retrospect, we regret that our decision to take out a section on dual-inheritance theory (DIT) appears to have been a source of some irritation and misunderstanding. O'Brien and Lycett, for example, come away with the impression that what we suggest is that culture ought to be viewed "as a system of descent with modification mediated by the pillars of inheritance, variation, and sorting." No wonder that they think we are reinventing the wheel! Kohler summarizes this critique in a constructive way: "Andersson et al. might have considered developing their ideas within the context provided by DIT. At a minimum, they should give clear reasons for not doing so." We will here try to do the latter, and by that to at least partly do the former by explaining how DIT is related to the proposed approach. Then we will move on to more specific comments.

The choice overall was to contextualize our story more with debates about transitions and large-scale patterns than with debates about the modeling of microlevel mechanisms. We see DIT as a valuable source of models, but our approach for understanding the evolutionary process as a whole is very different. As Laubichler argues, our work is to be understood precisely as part of a greater project of understanding innovation in complex adaptive systems - and by innovation we mean radical rather than just gradual innovation.

DIT focuses strongly on population thinking-whether it is selection, drift, or other sorting mechanisms that are in action-as the key to the whole story of evolution. Let us first stress that we have nothing against population thinkingwe think it is essential for understanding evolution, and it interests us greatly (see, e.g., Andersson 2011a). But population thinking is basically all that DIT can deal with, and we think that more is needed. Boyd and Richerson (2005), for example, describe DIT as a combination of population genetics and rational choice theory, and we believe that this does sum it up quite well. DIT never strays far from this set of basic models, which also embody what is seen as the essence of what it means to be scientific in the first place. These basic tools bring analytical power, but they also bring strong constraints and biases in terms of what types of questions that can be addressed. Radical innovation - that is, transformation 
of social structure through qualitative novelty-is something that we think is absolutely central for understanding cultural evolution, and it is not in the set of things that DIT does a good job of modeling. Here we need also organization thinking (see Lane et al. 2009; Read and Lane 2008), although we think Kohler is right that systemic perspectives have tended to deemphasize population thinking too much. We do not agree, however, with Kohler's comment that "DIT explicitly deals with 'how culture is organized, how it develops, and how it interacts with other processes."'

We are certainly of the opinion that bottom-up modeling is necessary for understanding cultural evolution-how would we otherwise be able to understand emergence in complex and massively parallel dynamical systems? But we do not think that the microlevel can be seen as prior to higher levels of organization. Microdynamics generates high-level organization-but high-level organization also scaffolds microdynamics so the arrow does not just point from the bottom and up. Consequently, we think that it is important not to postpone the task of getting the macroscopic patterns right for an undefined future (that we think will never arrive) where they would be explained from the microlevel. Getting this right, we think, demands being more methodologically synthetic and broad than is the case with DIT.

As suggested by Richerson and Bettinger, let us consider Alex Mesoudi's (2011) book Cultural Evolution as a recent and reasonably representative statement by a major contributor to the DIT tradition. We first note that Mesoudi covers evolutionary developmental theory in about one page and uses the term in a much narrower sense than we do-which includes a host of partly aligned traditions that pay attention to structure on meso and macro levels; see also table 1 in Read's comment. We concede that using the term the way that we do can be confusing, even if we specify that we use it as an umbrella term.

It is also instructive to see how Mesoudi (2011) differentiates between a general Darwinian and a neo-Darwinian account of cultural evolution. He does this in a way that is very different from ours and that illustrates why DIT researchers probably find our account confusing: they may not agree with us that DIT is neo-Darwinian. Mesoudi's points include: whether evolution is Darwinian or Lamarckian, whether transmission is particulate or not, and whether variation is blind or not. These are classical issues that have been debated-in our opinion, with little obvious progress and consequence-in the context of universal Darwinism, evolutionary economics, and DIT for a long time; we have participated to some extent in that debate (e.g., Andersson 2008, 2011b).

Mesoudi concludes that cultural evolution is primarily Darwinian rather than neo-Darwinian. These points of differentiation, however, represent more incremental adjustments to the same formalist framework. The rise of developmental thinking, by contrast, signifies a break with the view that evolution can be understood on a single level of organisms or genes, that is, solely in terms of population thinking; see also Laubichler's comment. While DIT importantly does challenge a number of standard neo-Darwinian assumptions, such as by introducing frequency-dependent fitness and other selection biases, the picture that Mesoudi paints (and that is amply evident in the literature) is still fundamentally neoDarwinian on points that we see as much more significant than those listed above.

We are well aware that-as O'Brien and Lycett point outsome of the elements that we consider to be part of evolutionary developmental theorizing-not least niche construction theory (NCT) - have been used previously in the context of cultural evolution. But it is certainly true that the bulk of the applications of NCT to culture has concerned how culture affects genes. This is not without importance to us, but what is more central to our argument is how culture affects culture. That is, pointing the reciprocal arrow of causation in NCT back from culture to culture. This is something that both Odling-Smee and Laland (personal communication, 2013) see as an interesting possible development of NCT that has not been much pursued so far.

The points raised by Hovers and Belfer-Cohen about our rendition of the MP-UP transition ${ }^{10}$ illustrate another effect of strong competition for space in this paper. This is important to respond to for two reasons. The first is that we maintain that although other resources besides meat were clearly used during the MP (e.g., El Zaatari et al. 2011; Henry, Brooks, and Piperno 2011), we find no evidence that the strong reliance on a big game meat diet during the MP (and indeed well past it) as such would be in question. MP strategies for utilizing plant resources do not appear to come close either to MP hunting strategies in complexity or to plant-processing strategies in the UP (Piperno et al. 2004; Revedin et al. 2010). We would be inclined to interpret these as minor regimes, while big game hunting would be the single major foodgetting regime. So although a more thorough case study would go more into such details, we think that the main message still stands.

The second is the question of how to evaluate the case study examples. They are not unique predictions of the framework, and the framework could easily be used for constructing very different accounts-just like any Darwinian framework can. There is a lot of room for disagreeing on how history played itself out. What we advocate is a new way of conceptualizing the evolution of culture-not a single model of what happened, although of course we have our favorite ideas, subject to revision over time in the face of evidence.

This brings us to the issue of whether this is really a new way of looking at cultural evolution. We readily admit that we need to better integrate intellectual antecedents such as Flannery. This includes also some of the recent work that O'Brien and Lycett point us to, where O'Brien and others,

10. And partly to our hypothesized role of lithics, although we do not see how their conclusion about the role of lithics flows from their statement about its origins. 
for example, apply Michael Schiffer's models (e.g., O’Brien and Bentley 2011). Schiffer's work has inspired us greatly, but we do need to integrate this further. We are thereby certainly not the first to find new ways of understanding cultural evolution through feedback processes, and older systems theories are treasure troves for our purposes. But there is an important difference between systems theories and complex-systems theories. Emergence-in the sense of macroscopic features being irreducible (in practice or in principle; e.g., Bedau 1997, 2003; Chalmers 2006) - is central to systems theories and complexsystems theories alike. But while systems theories posit emergence, complex-systems theories explicitly study emergence. Systems theories predefine systems as "connected boxes" and address the dynamics of these systems while complex-systems theories ask how these "boxes" and their connections appear and change over time. We think that combining these approaches to systems will be necessary, and that is the direction in which we would like to go.

Davidson raises the question of whether the GBY really represents a single culture that lasted across $50 \mathrm{ky}$. It is of course very hard to have an intuition for whether that is reasonable or not, but it does raise some interesting questions. We think three points are worth mentioning in this context. One is that parts of culture could be very persistent, while other parts may be highly ephemeral. More specifically, some of the "bottom parts" that we argue would be generatively entrenched we think could survive both 50 and $500 \mathrm{ky}$ and much longer. We agree that there is ample room for transmission failure and would like to additionally point to our own work on precisely that issue (Andersson 2011a, 2013).

The second point is that the capacity of earlier hominins for maintaining culture appears to have been consistently underestimated. Recent research about the cultural capacity of great apes suggests rethinking the minimal cultural capabilities of early hominins. To take only one example, Mercader et al. (2007) archaeologically trace chimpanzee nut cracking back 4,300 years; 4,300 surely is not 500,000 , but 4,300 is a lower bound, and $H$. erectus were not chimpanzees.

The third point is that the issue of culture and transmission is typically posed as whether features are maintained using transmission or whether they are externally stabilized (e.g., by properties of the raw material and hominin physiology) and thereby cannot be properly described as cultural; this pertains also to a comment by O'Brien and Lycett. But we think one factor does not rule out the other. Say that limitations apply on the capacity for transmitting cultural knowledge (e.g., Andersson 2011a; Henrich 2004), would it not be reasonable that artifacts that are strongly externally scaffolded would be attractive since they would obtain a lot of stability "for free" in terms of transmission? In our view, culture is not just transmission-it is a whole system that stabilizes itself by whatever means and that we could just as well describe as autopoietic as being based on transmission.

We agree with Read that we did not address the question of why Homo and Pan diverged culturally in such a drastic way, and we view this as an example of a case that should be pursued. We also agree that the question of group cohesion and the notion that Homo reinvented a way of maintaining large groups from scratch during the course of the Paleolithic are highly interesting, and we think that it falls well into the type of explanations that our framework is intended to help producing. Concerning the expanded synthesis: finding a suitable umbrella term is a problem, and we thank Read for pointing us to this table. The expanded synthesis, we would like to note, is not as well synthesized as the modern synthesis, and it contains methodological friction that the Modern Synthesis did not contain.

Laubichler's comment complements the article well by making some of the arguments about the parallel biological case much better than we were able to do it. We fully agree that this is part of a greater project of understanding innovation in complex adaptive systems, and we think this is also what is so exciting about it: the interest for coming up with such a theory is very wide, and we believe that it is the logical next step that needs to be taken-rather than to keep holding our breath for a single-level bottom-up understanding to explain it all.

—Claes Andersson, Anton Törnberg, and Petter Törnberg

\section{References Cited}

Alchian, A. A. 1950. Uncertainty, evolution and economic theory. Journal of Political Economy 58:211-222. [PJR/RLB]

Andersson, C. 2008. Sophisticated selectionism as a general theory of knowledge. Biology and Philosophy 23(2):229-242.

. 2011a. Palaeolithic punctuations and equilibria: did retention rather than invention limit technological evolution? PaleoAnthropology 2011:243259.

- 2011b. Splitting the replicator: generalized Darwinism and the place of culture in nature. Journal of Economic Behavior and Organization 80: 657-669.

- 2013. Fidelity and the emergence of stable and cumulative sociotechnical systems. PaleoAnthropology 2013:88-103.

Andrefsky, W. 2009. The analysis of stone tool procurement, production, and maintenance. Journal of Archaeological Research 17(1):65-103.

Arthur, W. 2011. Evolution: a developmental approach. Chichester: Wiley-Blackwell.

Bedau, M. 1997. Weak emergence. In Philosophical perspectives: mind, causation, and world, vol. 11. J. Tomberlin, ed. Pp. 375-399. Oxford: Blackwell. . 2003. Downward causation and the autonomy of weak emergence. Principia Revista Internacional de Epistemologica 6:5-50.

Bednarik, R. G. 2003. Seafaring in the Pleistocene. Cambridge Archeological Journal 13(1):41-66.

. 2011. The human condition. New York: Springer.

Bettinger, R. L. 1991. Hunter-gatherers: archaeological and evolutionary theory. New York: Plenum. [PJR/RLB]

Bettinger, R. L., and J. W. Eerkens. 1999. Point typologies, cultural transmission, and the spread of bow-and-arrow technology in the prehistoric Great Basin. American Antiquity 64:231-242. [MJO/SJL]

Beyries, S. 1993. Are we able to determine the function of the earliest Palaeolithic tools? In The use of tools by non-human primates. A. Berthelet and J. Chavaillon, eds. Pp. 225-236. Oxford: Clarendon.

Binford, Lewis R. 2001. Where do research problems come from? American Antiquity 66:669-678. [EH/AB-C]

Bocquet-Appel, J.-P., and A. Tuffreau. 2009. Technological responses of Neanderthals to macroclimatic variations. Human Biology 81:287-307.

Boyd, Robert, and Peter J. Richerson. 1985. Culture and the evolutionary process. Chicago: University of Chicago Press. [TAK, MJO/SJL, PJR/RLB] 
Press.

Braun, D. R., M. J. Rogers, J. W. K. Harris, S. J. Walker. 2008. Landscapescale variation in hominin tool use: evidence from the Developed Oldowan. Journal of Human Evolution 55(6):1053-1063.

Campbell, D. T. 1960. Blind variation and selective retention in creative thought as in other knowledge processes. Psychological Review 67:380-400. [PJR/RLB]

Cavalli-Sforza, L. L., and Marcus W. Feldman. 1981. Cultural transmission and evolution: a quantitative approach. Princeton, NJ: Princeton University Press. [TAK, MJO/SJL, PJR/RLB]

Cerling, Thure E., Fredrick Kyalo Manthi, Emma N. Mbua, Louise N. Leakey, Meave G. Leakey, Richard E. Leakey, Francis H. Brown, et al. 2013. Stable isotopebased diet reconstructions of Turkana Basin hominins. Proceedings of the National Academy of Sciences, doi:10.1073/pnas.1222568110. [EH/AB-C]

Chalmers, D. J. 2006. Strong and weak emergence. In The re-emergence of emergence. P. Clayton and P. Davies, eds. Pp. 244-256. Oxford: Oxford University Press.

Davidson, I., and W. C. McGrew. 2005. Stone tools and the uniqueness of human culture. Journal of the Royal Anthropological Institute 11(4):793-817.

Dawkins, R. 1989. Darwinism and human purpose. In Human origins. J. R. Durant, ed. Pp. 137-143. Oxford: Clarendon. [EH/AB-C]

Delagnes, A., and L. Meignen. 2006. Diversity of lithic production systems during the Middle Paleolithic in France. In Transitions before the transition. E. Hovers and S. L. Kuhn, eds. Pp. 295-303. Berlin: Springer.

De la Torre, I., R. Mora, M. Dominguez-Rodrigo, L. de Luque, and L. Alcala. 2003. The Oldowan industry of Peninj and its bearing on the reconstruction of the technological skills of Lower Pleistocene hominids. Journal of Human Evolution 44(2):203-224. [ID]

Domínguez-Rodrigo, M., T. R. Pickering, S. Semaw, and M. J. Rogers. 2005. Cutmarked bones from Pliocene archaeological sites at Gona, Afar, Ethiopia: implications for the function of the world's oldest stone tools. Journal of Human Evolution 48(2):109-121.

Domínguez-Rodrigo, M., J. Serrallonga, J. Juan-Tresserras, L. Alcala, and L. Luque. 2001. Woodworking activities by early humans: a plant residue analysis on Acheulian stone tools from Peninj (Tanzania). Journal of Human Evolution 40(4):289-299.

Eerkens, J. W., and C. P. Lipo. 2005. Cultural transmission, copying errors, and the generation of variation in material culture and the archaeological record. Journal of Anthropological Archaeology 24:316-334. [MJO/SJL, PJR/ RLB]

El Zaatari, S., F. E. Grine, P. S. Ungar, and J.-J. Hublin. 2011. Ecogeographic variation in Neandertal dietary habits: evidence from occlusal molar microwear texture analysis. Journal of Human Evolution 61(4):411-424, doi: 10.1016/j.jhevol.2011.05.004.

Enquist, M., S. Ghirlanda, and K. Eriksson. 2011. Modelling the evolution and diversity of cumulative culture. Philosophical Transactions of the Royal Society B 366:412-423. [MJO/SJL]

Flannery, Kent. 1968. Archeological systems theory and early Mesoamerica. In Anthropological archeology in the Americas. B. J. Meggers, ed. Pp. 67-87. Washington, DC: Anthropological Society of Washington. [TAK]

- 1969. [Untitled]. In The domestication and exploitation of plants and animals. P. J. Ucko and G. W. Dimbleby, eds. Pp. 73-100. Chicago: Aldine.

Foley, R., and M. M. Lahr. 2003. On stony ground: lithic technology, human evolution, and the emergence of culture. Evolutionary Anthropology 12:109122.

Gamble, C. 2010. Technologies of separation and the evolution of social extension. In Social brain, distributed mind. R. Dunbar, C. Gamble, and J. Gowlett, eds. Pp. 17-42. Oxford: Oxford University Press. [DWR]

Gaudzinski, S. 2006. Monospecific or species-dominated faunal assemblages during the Middle Paleolithic in Europe. In Transitions before the transition: evolution and stability in the Middle Paleolithic and the Middle Stone Age. E. Hovers and S. L. Kuhn, eds. Pp. 137-147. New York: Springer Science. Gaudzinski-Windheuser, S., and L. Niven. 2009. Hominin subsistence patterns during the Middle and Late Paleolithic in northwestern Europe. In The evolution of hominin diets: integrating approaches to the study of Palaeolithic subsistence. J.-J. Hublin, and M. Richards, eds. Pp. 99-109. New York: Springer Science.

Geels, F., and J. Schot. 2007. Typology of sociotechnical transition pathways. Research Policy 36(3):399-417.

Geels, F. W. 2010. Ontologies, socio-technical transitions (to sustainability), and the multi-level perspective. Research Policy 39(4):495-510.

Geels, F. W., and R. Kemp. 2012. The multi-level perspective as a new per- spective for studying socio-technical transitions. In Automobility in transition? A socio-technical analysis of sustainable transport. F. Geels, R. Kemp, G. Dudley, and G. Lyons, eds. Pp. 49-79. New York: Routledge.

Gerard, R. W., A. Rapoport, and C. Kluckhohn. 1956. Biological and cultural evolution: some analogies and explorations. Behavioral Science 1(1):6-34. [PJR/RLB]

Goren-Inbar, N. 2011. Culture and cognition in the Acheulian industry: a case study from Gesher Benot Ya'aqov. Philosophical Transactions of the Royal Society B: Biological Sciences 366(1567):1038-1049.

Goren-Inbar, N., N. Alperson, M. E. Kislev, O. Simchoni, Y. Melamed, A. Ben-Nun, and E. Werker. 2004. Evidence of hominin control of fire at Gesher Benot Ya'aqov, Israel. Science 304(5671):725-727.

Goren-Inbar, N., S. Belitzky, K. Verosub, E. Werker, M. Kislev, A. Heimann, I. Carmi, and A. Rosenfeld. 1992. New discoveries at the Middle Pleistocene Acheulian site of Gesher Benot Yaaqov, Israel. Quaternary Research 38:117128.

Goren-Inbar, N., G. Sharon, Y. Melamed, and M. Kislev. 2002. Nuts, nut cracking, and pitted stones at Gesher Benot Ya'aqov, Israel. Proceedings of the National Academy of Sciences USA 99(4):2455-2460.

Gould, S. J., and R. C. Lewontin. 1979. The Spandrels of San Marco and the Panglossian paradigm: a critique of the adaptationist programme. Proceedings of the Royal Society of London 205:581-598.

Gould, S. J., and E. S. Vrba. 1982. Exaptation-a missing term in the science of form. Paleobiology 8:4-15.

Griffiths, P. E., and R. D. Gray. 1994. Developmental systems and evolutionary explanation. Journal of Philosophy 91:277-304.

Hamilton, M. J., and B. Buchanan. 2009. The accumulation of stochastic copying errors causes drift in culturally transmitted technologies: quantifying Clovis evolutionary dynamics. Journal of Anthropological Archaeology 28:55-69. [MJO/SJL]

Heinzelin, J. D., J. D. Clark, T. White, W. Hart, P. Renne, G. Woldegabriel, Y. Beyene, and E. Vrba. 1999. Environment and behavior of 2.5-millionyear-old Bouri hominids. Science 284(5414):625-629.

Henrich, J. 2004. Demography and cultural evolution: how adaptive cultural processes can proclude maladaptive losses-the Tasmanian case. American Antiquity 69(2):197-214.

Henry, Amanda G., Alison S. Brooks, and Dolores R. Piperno. 2011. Microfossils in calculus demonstrate consumption of plants and cooked foods in Neanderthal diets (Shanidar III, Iraq; Spy I and II, Belgium). Proceedings of the National Academy of Sciences 108:486-491.

Henshilwood, C. S., and C. W. Marean. 2003. The origin of modern human behavior. Current Anthropology 44(5):627-651.

Hockett, Bryan. 2012. The consequences of Middle Paleolithic diets on pregnant Neanderthal women. Quaternary International 264:78-82. [EH/AB-C]

Hoffecker, J. F. 2009. Neanderthal and modern human diet in Eastern Europe. In The evolution of hominin diets: integrating approaches to the study of Palaeolithic subsistence. J.-J. Hublin, and M. P. Richards, eds. Pp. 87-98. New York: Springer Science.

Hovers, E., and S. L. Kuhn. 2006. Transitions before the transition. Berlin: Springer.

Hovers, Erella. 2012. Invention, re-invention, innovations: makings of the Oldowan. In Origins of human creativity and innovation: developments in quaternary science, vol. 16. S. Elias, ed. Pp. 49-65. Amsterdam: Elsevier. [EH/AB-C]

Hovers, Erella, and Anna Belfer-Cohen. 2006. "Now you see it, now you don't"-modern human behavior in the Middle Paleolithic. In Transitions before the transition: evolution and stability in the Middle Paleolithic and Middle Stone Age. E. Hovers and S. L. Kuhn, eds. Pp. 295-304. New York: Springer. [EH/AB-C]

Keeley, L., and N. Toth. 1981. Microwear polishes on early stone tools from Koobi Fora, Kenya. Nature 293:464-465.

Kempe, M., S. J. Lycett, and A. Mesoudi. 2012. An experimental test of the accumulated copying error model of cultural mutation for Acheulean handaxe size. PLoS ONE 7(11)/e48333:1-7. [MJO/SJL]

Kendal, J., J. J. Tehrani, and J. Odling-Smee. 2011. Human niche construction in interdisciplinary focus. Philosophical Transactions of the Royal Society $B$ 366:785-792. [MJO/SJL]

Klein, R. G. 1995. Anatomy, behavior and modern human origins. Journal of World Prehistory 9:167-198.

. 2000. Archeology and the evolution of human behavior. Evolutionary Anthropology 9(1):17-36.

Klein, R. G., and B. Edgar. 2002. The dawn of human culture. New York: Wiley. 
Kohler, Timothy A. 2012. Complex systems and archaeology. In Archaeological theory today. 2nd ed. Ian Hodder, ed. Pp. 93-123. Cambridge: Polity. [TAK]

Kuhn, S. L. 2004. Evolutionary perspectives on technology and technological change. World Archaeology 36:561-570. [MJO/SJL]

- 2006. Trajectories of change in the Middle Paleolithic of Italy. In Transitions before the transition. E. Hovers and S. L. Kuhn, eds. Pp. 109120. Berlin: Springer.

Kuhn, S. L., and M. Stiner. 2001. The antiquity of hunter-gatherers. In Huntergatherers, an interdisciplinary perspective. C. Panter-Brick, R. H. Layton, and P. Rowley-Conwy, eds. Pp. 99-142. Cambridge: Cambridge University Press.

. 2006. What's a mother to do? The division of labor among Neandertals and modern humans in Eurasia. Current Anthropology 47(6):953980.

Laland, K. N., J. R. Kendal, and G. R. Brown. 2007. The niche construction perspective. Journal of Evolutionary Psychology 5(1):51-66.

Laland, K. N., F. J. Odling-Smee, and S. Myles. 2010. How culture shaped the human genome: bringing genetics and the human sciences together. Nature Reviews Genetics 11:137-148. [MJO/SJL, PJR/RLB]

Laland, Kevin N., Kim Sterelny, John Odling-Smee, William Hoppitt, and Tobias Uller. 2011. Cause and effect in biology revisited: is Mayr's proximate-ultimate dichotomy still useful? Science 334:1512-1516. [TAK]

Lane, D., 2002. Complexity and local interactions: towards a theory of industrial districts. In Complexity and industrial clusters. A. C. Quadrio and M. Fortis, eds. Pp. 65-82. Berlin: Springer.

Lane, D., and R. Maxfield. 2005. Ontological uncertainty and innovation. Journal of Evolutionary Economics 15:3-50.

Lane, D. A. 2011. Complexity and innovation dynamics. In Handbook on the economic complexity of technological change. C. Antonelli, ed. Pp. 63-80. Cheltenham: Edward Elgar.

Lane, D. A., R. R. Maxfield, D. W. Read, and S. E. van der Leeuw. 2009. From population to organization thinking. In Complexity Perspectives in Innovation and Social Change. D. A. Lane, S. E. van der Leeuw, D. Pumain, and G. B. West, eds. Pp. 11-42. Berlin: Springer.

Leaf, M., and D. Read. 2012. The conceptual foundation of human society and thought: anthropology on a new plane. Lanham, MD: Lexington Books. [DWR]

Leakey, M. D. 1971. Olduvai Gorge, vol. 3 of Excavations in Beds I and II, 1960-1963. Cambridge: Cambridge University Press. [ID]

Lewontin, R. C. 1983. Gene, organism, and environment. In Evolution from molecules to men. D. S. Bendall, ed. Pp. 273-285. Cambridge: Cambridge University Press. [MJO/SJL]

Lorentz, K. 1977. Behind the mirror. London: Methuen.

Lumsden, C. J., and E. O. Wilson. 1981. Genes, mind, and culture: the coevolutionary process. Cambridge, MA: Harvard University Press. [PJR/RLB]

Lycett, S. J. 2008. Acheulean variation and selection: does handaxe symmetry fit neutral expectations? Journal of Archaeological Science 35:2640-2648. [MJO/SJL]

. 2011. "Most beautiful and most wonderful": those endless stone tool forms. Journal of Evolutionary Psychology 9:143-171. [MJO/SJL]

Lyman, R. L., and M. J. O’Brien. 1998. The goals of evolutionary archaeology: history and explanation. Current Anthropology 39:615-652. [MJO/SJL]

Mania, D., and U. Mania. 2005. The natural and socio-cultural environment of Homo erectus at Bilzingleben, Germany. In The hominid individual in context. C. Gamble, and M. Porr, eds. Pp. 98-114. Oxon: Routledge.

Mania, D., U. Mania, and E. Vlcek. 1994. Latest finds of skull remains of Homo erectus from Bilzingsleben (Thuringia). Naturwissenschaften 81:123127.

Mayr, E., and W. B. Provine, eds. 1980. The evolutionary synthesis. Cambridge, MA: Harvard University Press. [DWR]

Mazza, P. P. A., F. Martini, B. Sala, M. Magi, M. P. Colombini, G. Giachi, F. Landucci, C. Lemorini, F. Modugno, and E. Ribechini. 2006. A new Palaeolithic discovery: tar-hafted stone tools in a European Mid-Pleistocene bone-bearing bed. Journal of Archaeological Science 33(9):1310-1318.

McBrearty, S. 2007. Down with the revolution. In The human revolution revisited. P. A. Mellars, K. Boyle, O. Bar-Yosef, and C. B. Stringer, eds. Pp. 133-151. Cambridge: McDonald Institute for Archaeological Research.

McBrearty, S., and A. S. Brooks. 2000. The revolution that wasn't: a new interpretation of the origin of modern human behavior. Journal of Human Evolution 39:453-563.

McCall, G. S. 2006. Multivariate perspectives on change and continuity in Middle Stone Age lithics from Klasies River Mouth, South Africa. Journal of Human Evolution 51:429-439.
McGrew, William C. 2010. Chimpanzee technology. Science 328:579-580. [EH/ AB-C]

Mercader, J., H. Barton, J. Gillespie, J. Harris, S. Kuhn, R. Tyler, and C. Boesch. 2007. 4,300-year-old chimpanzee sites and the origins of percussive stone technology. Proceedings of the National Academy of Sciences USA 104(9): 3043-3408, doi:10.1073/pnas.0607909104.

Mesoudi, A. 2011. Cultural evolution: how Darwinian theory can explain human culture and synthesize the social sciences. Chicago: University of Chicago Press.

Mesoudi, A., and M. J. O’Brien. 2008. The learning and transmission of hierarchical cultural recipes. Biological Theory 3:63-72. [MJO/SJL]

- 2009. Placing archaeology within a unified science of cultural evolution. In Pattern and process in cultural evolution. S. Shennan, ed. Pp. 2132. Berkeley: University of California Press. [MJO/SJL]

Mesoudi, Alex, Andrew Whiten, and Kevin N. Laland. 2006. Towards a unified science of cultural evolution. Behavioral and Brain Sciences 29:329-383. [TAK]

Munro, N. D. 2004. Zooarchaeological measures of hunting pressure and occupation intensity in the Natufian. Current Anthropology 45(suppl.):S5S33. [ID]

Neiman, F. D. 1995. Stylistic variation in evolutionary perspective: inferences from decorative diversity and interassemblage distance in Illinois Woodland ceramic assemblages. American Antiquity 60:7-36. [MJO/SJL]

Noble, W., and I. Davidson. 1996. Human evolution, language and mind. Cambridge: Cambridge University Press. [ID]

Norton, C. J., K. Bae, J. W. K. Harris, and H. Lee. 2006. Middle Pleistocene handaxes from the Korean Peninsula. Journal of Human Evolution 51(5): 527-536.

O'Brien, M. J., and R. A. Bentley. 2011. Stimulated variation and cascades: two processes in the evolution of complex technological systems. Journal of Archaeological Method and Theory 18(4):309-335, doi:10.1007/s10816011-9110-7.

O'Brien, M. J., and K. N. Laland. 2012. Genes, culture, and agriculture: an example of human niche construction. Current Anthropology 53:434-470. [MJO/SJL]

O’Brien, M. J., and R. L. Lyman. 2000. Applying evolutionary archaeology: a systematic approach. New York: Kluwer/Plenum. [MJO/SJL]

. 2002. Evolutionary archeology: current status and future prospects. Evolutionary Anthropology 11:26-36. [MJO/SJL]

O’Brien, M. J., R. L. Lyman, A. Mesoudi, and T. L. VanPool. 2010. Cultural traits as units of analysis. Philosophical Transactions of the Royal Society $B$ 365:3797-3806. [MJO/SJL]

O'Connell, J. F. 2006. How did modern humans replace Neanderthals? insights from hunter-gatherer ethnography and archaeology. In Neanderthals and modern humans meet. N. J. Conard, ed. Pp. 43-64. Tübingen: Kerns Publications in Prehistory.

Odling-Smee, F. J., K. N. Laland, and M. W. Feldman. 2003. Niche construction: the neglected process in evolution. Monographs in Population Biology 37. Princeton, NJ: Princeton University Press.

Oyama, S., P. Griffiths, and P. Gray. 2001. Cycles of contingency: developmental systems and evolution. London: MIT Press.

Pérez-Pérez, A., V. Espurz, J. M. Bermúdez de Castro, M. Antoinette de Lumley, and D. Turbón. 2003. Non-occlusal dental microwear variability in a sample of Middle and Late Pleistocene human populations from Europe and the Near East. Journal of Human Evolution 44(4):497-513.

Petraglia, M. D., and C. Shipton. 2008. Large cutting tool variation west and east of the Movius Line. Journal of Human Evolution 55(6):962-966.

Pétrequin, P., and A.-M. Pétrequin. 1993. Écologie d'un outil: la hache de pierre en Irian Jaya (Indonésie). Paris: CNRS.

Pigliucci, M., and G. B. Müller. 2010a. Elements of an extended evolutionary synthesis. In Evolution: the extended synthesis. M. Pigliucci and G. B. Müller, eds. Pp. 3-18. Cambridge, MA: MIT Press. [DWR]

- eds. 2010b. Evolution: the extended synthesis. Cambridge, MA: MIT Press. [DWR]

Piperno, D. R., E. Weiss, I. Holst, and D. Nadel. 2004. Processing of wild cereal grains in the Upper Palaeolithic revealed by starch grain analysis. Nature 430(7000):670-673, doi:10.1038/nature02734.

Plummer, T. 2004. Flaked stones and old bones: biological and cultural evolution at the dawn of technology. American Journal of Physical Anthropology 39(suppl.):118-164.

Powell, A., S. Shennan, and M. G. Thomas. 2009. Late Pleistocene demography and the appearance of modern human behavior. Science 324:1298-1301. [EH/AB-C, PJR/RLB] 
Premo, Luke S., and Steve L. Kuhn. 2010. Modeling effects of local extinctions on culture change and diversity in the Paleolithic. PLoS ONE 5:e15582. [EH/AB-C]

Rabinovich, R., S. Gaudzinski-Windheuser, and N. Goren-Inbar. 2008. Systematic butchering of fallow deer (Dama) at the early middle Pleistocene Acheulian site of Gesher Benot Ya'aqov (Israel). Journal of Human Evolution 54(1):134-149.

Read, D. 2001. What is kinship? In The cultural analysis of kinship: the legacy of David Schneider and its implications for anthropological relativism. R. Feinberg and M. Ottenheimer, eds. Pp. 78-117. Urbana: University of Illinois Press. [DWR]

2007. Kinship theory: a paradigm shift. Ethnology 46:329-364. [DWR]

2012. How culture makes us human: primate evolution and the formation of human societies. Walnut Creek, CA: Left Coast. [DWR]

Read, D., and D. Lane. 2008. Darwinian evolution-broad enough for culture? Anthropology Today 24(2):1-2.

Read, D., D. Lane, and S. van der Leeuw. 2009. The innovation innovation. In Complexity perspectives in innovation and social change. D. Lane, D. Pumain, S. van der Leeuw, and G. West, eds. Pp. 43-84. Berlin: Springer. [DWR]

Read, Dwight, and Sander van der Leeuw. 2008. Biology is only part of the story. Philosophical Transactions of the Royal Society B: Biological Sciences 363:1959-1968. [EH/AB-C]

Revedin, A., B. Aranguren, R. Becattini, L. Longo, E. Marconi, M. M. Lippi, Natalia Skakun, Andrey Sinitsyn, Elena Spiridonova, and J. Svoboda. 2010. Thirty thousand-year-old evidence of plant food processing. Proceedings of the National Academy of Sciences USA 107(44):18815-18819, doi:10.1073/ pnas. 1006993107.

Richards, M., and E. Trinkaus. 2009. Isotopic evidence for the diets of European Neanderthals and early modern humans. Proceedings of the National Academy of Sciences 106(38):16034-16039.

Richards, M. P., P. B. Pettitt, E. Trinkaus, F. H. Smith, M. Paunović, and I. Karavanić. 2000. Neanderthal diet at Vindija and Neanderthal predation: the evidence from stable isotopes. Proceedings of the National Academy of Sciences USA 97(13):7663-7666.

Richerson, P. J., and R. Boyd. 2010. Gene-culture coevolution in the age of genomics. Proceedings of the National Academy of Sciences USA 107(suppl. 2):8985-8992. [PJR/RLB]

Roebroeks, W., and P. Villa. 2011. On the earliest evidence for habitual use of fire in Europe. Proceedings of the National Academy of Sciences USA 108(13):5209-5214.

Rolland, N. 2004. Was the emergence of home bases and domestic fire a punctuated event? a review of the Middle Pleistocene record in Eurasia. Asian Perspectives 43(2):248-280.

Rots, V., and P. Van Peer. 2006. Early evidence of complexity in lithic economy: core-axe production, hafting and use at Late Middle Pleistocene site 8-B11, Sai Island (Sudan). Journal of Archaeological Science 33(3):360-371.

Rots, V., P. Van Peer, and P. M. Vermeersch. 2011. Aspects of tool production, use, and hafting in Palaeolithic assemblages from Northeast Africa. Journal of Human Evolution 60(5):637-664.

Schiffer, M. B. 2005. The devil is in the details: the cascade model of invention processes. American Archaeology 70(3):485-502.

Schlebusch, C. M., P. Skoglund, P. Sjödin, L. M. Gattepaille, D. Hernandez, F. Jay, S. Li, et al. 2012. Genomic variation in seven Khoe-San groups reveals adaptation and complex African history. Science 338(6105):374-379.

Schumpeter, J., 1934. The theory of economic development. Cambridge, MA: Harvard University Press.

Semaw, S., M. J. Rogers, J. Quade, P. Renne, R. Butler, M. Domínguez-Rodrigo, D. Stout, W. Hart, T. Pickering, and S. Simpson. 2003. 2.6-million-yearold stone tools and associated bones from OGS-6 and OGS-7, Gona, Afar, Ethiopia. Journal of Human Evolution 45:169-177.

Sharon, G., N. Alperson-Afil, and N. Goren-Inbar. 2011. Cultural conservatism and variability in the Acheulian sequence of Gesher Benot Ya'aqov. Journal of Human Evolution 60(4):387-97.

Shea, J. J. 2011. Homo sapiens is as Homo sapiens was-behavioral variability versus "behavioral modernity" in Paleolithic archaeology. Current Anthropology 52(1):1-35.

Shennan, S. 2002. Genes, memes and human history: Darwinian archaeology and cultural evolution. London: Thames \& Hudson. [MJO/SJL, PJR/RLB]
Shennan, Stephen. 2001. Demography and cultural innovation: a model and its implications for the emergence of modern human culture. Cambridge Archaeological Journal 11:5-16. [EH/AB-C]

. 2012. Darwinian cultural evolution. In Archaeological theory today. 2nd ed. Ian Hodder, ed. Pp. 15-36. Cambridge: Polity. [TAK]

Shubin, N., C. Tabin, and S. Carroll. 1997. Fossils, genes and the evolution of animal limbs. Nature 388:639-648.

Snodgrass, J. J., R. W. Leonard, and M. L. Robertson. 2009. The energetics of encephalization in early hominids. In The evolution of hominin diets: integrating approaches to the study of Palaeolithic subsistence. J.-J. Hublin and M. P. Richards, eds. Pp. 15-29. New York: Springer Science.

Soriano, S., P. Villa, and L. Wadley. 2007. Blade technology and tool forms in the Middle Stone Age of South Africa: the Howiesons Poort and postHowiesons Poort at Rose Cottage Cave. Journal of Archaeological Science 34(5):681-703.

Speth, John D. 2010. The paleoanthropology and archaeology of big-game hunting: protein, fat, or politics? New York: Springer. [EH/AB-C]

Steele, T. E. 2010. A unique hominin menu dated to 1.95 million years ago. Proceedings of the National Academy of Sciences USA 107(24):10771-10772.

Sterelny, K. 2011. From hominins to humans: how sapiens became behaviourally modern. Philosophical Transactions of the Royal Society B: Biological Sciences 366(1566):809-22.

Stiner, M. C. 2002. Carnivory, coevolution, and the geographic spread of the genus Homo. Journal of Archaeological Research 10(1):1-63.

Stiner, M. C., and S. L. Kuhn. 2006. Changes in the connectedness and resilience of Paleolithic societies in Mediterranean ecosystems. Human Ecology 34(5):693-712.

Stiner, M. C., N. D. Munro, and T. A. Surovell. 2000. The tortoise and the hare. Current Anthropology 41(1):39-73.

Stout, D., S. Semaw, M. J. Rogers, and D. Cauche. 2010. Technological variation in the earliest Oldowan from Gona, Afar, Ethiopia. Journal of Human Evolution 58(6):474-491.

Thieme, H. 1997. Lower Palaeolithic hunting spears from Germany. Nature 385:807-810.

- 2005. The Lower Palaeolithic art of hunting. In The hominid individual in context. C. Gamble and M. Porr, eds. Pp. 115-132. Oxon: Routledge.

Tomasello, M. 1999. The cultural origins of human cognition. Cambridge, MA: Harvard University Press. [MJO/SJL]

Tostevin, G. B. 2013. Seeing lithics: a middle-range theory for testing cultural transmission in the Pleistocene. Oxford: Harvard University American School of Prehistoric Research/Oxbow. [PJR/RLB]

Ungar, Peter S. 2012. Dental evidence for the reconstruction of diet in African early Homo. Current Anthropology 53(suppl.):S318-S329. [EH/AB-C]

Ungar, Peter S., and Matt Sponheimer. 2011. The diets of early hominins. Science 334:190-193. [EH/AB-C]

Van der Leeuw, Sander, and James McGlade, eds. 1997. Time, process and structured transformation in archaeology. London: Routledge. [TAK]

Vekua, A., D. Lordkipanidze, G. P. Rightmire, J. Agusti, R. Ferring, G. Maisuradze, A. Mouskhelishvili, et al. 2002. A new skull of early Homo from Dmanisi, Georgia. Science 297(5578):85-89.

Villa, P., and M. Lenoir. 2009. Hunting and hunting weapons of the Lower and Middle Paleolithic of Europe. In The evolution of hominin diets: integrating approaches to the study of Palaeolithic subsistence. J.-J. Hublin and M. P. Richards, eds. Pp. 59-85. New York: Springer Science.

Vygotsky, L. S. 1978. Mind and society: the development of higher psychological processes. Cambridge, MA: Harvard University Press.

Wimsatt, W. C. 1999. Genes, memes and cultural heredity. Biology and Philosophy 14:279-310.

. 2013. Entrenchment and scaffolding: an architecture for a theory of cultural change. In Developing scaffolding in evolution, cognition and culture, L. R. Caporael, J. R. Griesemer, and W. C. Wimsatt, eds. Pp. 77-105. Cambridge, MA: MIT Press.

Wimsatt, W. C., and J. R. Griesemer. 2007. Reproducing entrenchments to scaffold culture: the central role of development in cultural evolution. In Integrating evolution and development: from theory to practice. R. Sansom and R. N. Brandon, eds. Pp. 227-324. Cambridge, MA: MIT Press. [DWR] Wood, B., and D. Strait. 2004. Patterns of resource use in early Homo and Paranthropus. Journal of Human Evolution 46(2):119-162. 